\title{
Calcium Dependence of Retrograde Inhibition by Endocannabinoids at Synapses onto Purkinje Cells
}

\author{
Stephan D. Brenowitz and Wade G. Regehr \\ Department of Neurobiology, Harvard Medical School, Boston, Massachusetts 02115
}

\begin{abstract}
Many types of neurons release endocannabinoids from their dendrites in response to elevation of intracellular calcium levels. Endocannabinoids then activate presynaptic cannabinoid receptors, thereby inhibiting neurotransmitter release for tens of seconds. A crucial step in understanding the physiological role of this retrograde signaling is to determine its sensitivity to elevations of postsynaptic calcium. Here we determine and compare the calcium dependence of endocannabinoid-mediated retrograde inhibition at three types of synapses onto cerebellar Purkinje cells. Previous studies have shown that Purkinje cell depolarization results in endocannabinoidmediated retrograde inhibition of synapses received from climbing fibers, granule cell parallel fibers, and inhibitory interneurons. Using several calcium indicators with a range of affinities, we performed a series of in situ and in vitro calibrations to quantify calcium levels in Purkinje cells. We found that postsynaptic calcium levels of $\sim 15 \mu \mathrm{M}$ are required for half-maximal retrograde inhibition at all of these synapses. In contrast, previous studies had suggested that endocannabinoid release could occur with slight elevations of calcium above resting levels, which implies that inhibition should be widespread and continuously modulated by subtle changes in intracellular calcium levels. However, our results indicate that such small changes in intracellular calcium are not sufficient to evoke endocannabinoid release. Instead, because of its high requirement for calcium, retrograde inhibition mediated by calcium-dependent endocannabinoid release from Purkinje cells will occur under more restricted conditions and with greater spatial localization than previously appreciated.
\end{abstract}

Key words: endocannabinoids; Purkinje cell; cerebellum; parallel fiber; climbing fiber; DSE; DSI

\section{Introduction}

Endocannabinoids act as retrograde signaling molecules in many brain regions, allowing postsynaptic cells to modulate their synaptic inputs (Kreitzer and Regehr, 2002; Wilson and Nicoll, 2002). Neurons release endocannabinoids such as anandamide and 2-arachidonylglycerol (Devane et al., 1992; Di Marzo et al., 1994; Stella et al., 1997), which modulate various ion channels (Mackie and Hille, 1992; Mackie et al., 1993; Twitchell et al., 1997), inhibit synaptic strength (Levenes et al., 1998; Takahashi and Linden, 2000), and alter the firing of presynaptic cells (Kreitzer et al., 2002) by activating receptors such as G-proteincoupled CB1 receptors (Matsuda et al., 1990; Devane et al., 1992). The synthesis and release of endocannabinoids involve the calcium-dependent cleavage of phospholipid precursors (Di Marzo et al., 1994; Stella et al., 1997) and do not require vesicle fusion (Ohno-Shosaku et al., 2001; Wilson and Nicoll, 2001). Determining the calcium sensitivity of endocannabinoidmediated modulation is crucial for understanding the conditions under which endocannabinoids are released and will help determine the mechanisms and functional role of this signaling system.

\footnotetext{
Received March 24, 2003; revised May 1, 2003; accepted May 2, 2003.

This work was supported by National Institutes of Health Grant R01-NS32405-01. We thank Michael Beierlein, Dawn Blitz, Solange Brown, Kelly Foster, Anatol Kreitzer, Patrick Safo, and Matthew Xu-Friedman for comments on this manuscript and Kim Irwin for technical assistance.

Correspondence should be addressed to Wade Regehr, 220 Longwood Avenue, Harvard Medical School, Boston, MA 02115. E-mail: wade_regehr@hms.harvard.edu.

Copyright $\odot 2003$ Society for Neuroscience $\quad$ 0270-6474/03/236373-12\$15.00/0
}

Retrograde signaling by endocannabinoids occurs throughout the brain but has been studied most extensively in the hippocampus and cerebellum. Depolarization of either CA1 pyramidal cells or Purkinje cells releases endocannabinoids, which activate presynaptic $\mathrm{CB} 1$ receptors and transiently reduce the strength of inhibitory synapses for tens of seconds (Kreitzer and Regehr, 2001a; Ohno-Shosaku et al., 2001; Wilson and Nicoll, 2001; Diana et al., 2002). This depolarization-induced suppression of inhibition (DSI) was shown to be calcium dependent as indicated by a requirement for extracellular calcium (OhnoShosaku et al., 1998), a voltage dependence similar to that of voltage-gated calcium channels (Lenz et al., 1998), and its sensitivity both to the duration of depolarization (Ohno-Shosaku et al., 1998) and to changes in intracellular calcium buffering (Lenz and Alger, 1999; Glitsch et al., 2000). In addition to DSI, depolarization-induced suppression of excitation (DSE) has been described at both parallel fiber (PF) and climbing fiber (CF) synapses onto Purkinje cells (Kreitzer and Regehr, 2001b; Maejima et al., 2001). Retrograde inhibition of all of these types of synapses is prevented by dialyzing the postsynaptic cell with calcium chelators (Pitler and Alger, 1992; Kreitzer and Regehr, 2001b). Moreover, for hippocampal synapses, photolytic elevation of calcium in the absence of depolarization is sufficient to induce retrograde synaptic inhibition (Wang and Zucker, 2001; Wilson and Nicoll, 2001). Thus, elevation of postsynaptic calcium $\left(\mathrm{Ca}_{\text {post }}\right)$ triggers release of endocannabinoids that serve as retrograde messengers for DSE and DSI.

The calcium dependence of endocannabinoid signaling has 
important implications for the magnitude and spatial extent of endocannabinoid actions. Previous studies of DSI suggest that endocannabinoid release requires only small increases in $\mathrm{Ca}_{\text {post }}$. In the cerebellum, an estimated increase of 40-200 nM in a Purkinje cell was sufficient to trigger retrograde inhibition (Glitsch et al., 2000). Such a low requirement for calcium suggests that substantial endocannabinoid release may occur tonically and that even modest activity levels could produce widespread synaptic inhibition. In contrast, studies of hippocampal DSI estimated that $\sim 4 \mu \mathrm{M} \mathrm{Ca} a_{\text {post }}$ is required to significantly suppress inhibitory synapses onto pyramidal cells (Wang and Zucker, 2001). This higher estimate suggests that greater levels of activity may be required to evoke endocannabinoid release from pyramidal cells than from Purkinje cells. Thus, previous studies provide differing estimates of the calcium dependence of retrograde endocannabinoid signaling at inhibitory synapses, and no studies to date have examined calcium sensitivity of retrograde inhibition at excitatory synapses.

Here we measure the calcium sensitivity of endocannabinoidmediated retrograde inhibition for climbing fiber, parallel fiber, and inhibitory synapses onto Purkinje cells. After taking a series of steps to determine absolute levels of $\mathrm{Ca}_{\text {post }}$, we found that for all three types of synapses, retrograde inhibition produced by Purkinje cell depolarization required $\mathrm{Ca}_{\text {post }}$ of $\sim 15 \mu \mathrm{M}$. In contrast to previous reports that endocannabinoid signaling is highly sensitive to calcium, our findings demonstrate that very large calcium signals are required to activate the endocannabinoid signaling system.

\section{Materials and Methods}

Electrophysiology. Parasagittal slices (300 $\mu \mathrm{m}$ thick) were cut from the cerebellar vermis of 10- to 12-d-old Sprague Dawley rats. Dissections were performed in ice-cold sucrose solution containing (in mM): 78 $\mathrm{NaCl}, 26 \mathrm{NaHCO}_{3}, 68$ sucrose, 25 glucose, $2.5 \mathrm{KCl}, 1.25 \mathrm{NaH}_{2} \mathrm{PO}_{4}-\mathrm{H}_{2} \mathrm{O}$, $7 \mathrm{MgCl}_{2}, 0.5 \mathrm{CaCl}_{2}$. Slices were incubated for $30 \mathrm{~min}$ at $34^{\circ} \mathrm{C}$ in sucrose solution and then transferred to saline solution containing (in $\mathrm{mM}$ ): 125 $\mathrm{NaCl}, 26 \mathrm{NaHCO}_{3}, 1.25 \mathrm{NaH}_{2} \mathrm{PO}_{4}-\mathrm{H}_{2} \mathrm{O}, 2.5 \mathrm{KCl}, 1 \mathrm{MgCl}_{2}, 2 \mathrm{CaCl}_{2}, 25$ glucose, and allowed to cool to room temperature. All solutions were bubbled with $95 \% \mathrm{O}_{2} / 5 \% \mathrm{CO}_{2}$.

Whole-cell voltage-clamp recordings of Purkinje cells were obtained using glass electrodes (1.5-2.5 M $\Omega$ ) filled with an intracellular solution containing (in mM): $135 \mathrm{CsMeSO}_{4}, 15 \mathrm{CsCl}, 15 \mathrm{HEPES}, 0.2$ EGTA, 1 $\mathrm{MgCl}_{2}, 2 \mathrm{MgATP}, 0.3 \mathrm{NaGTP}, 10$ phosphocreatine, 2 QX-314, and 20 TEA. The holding potential was $-60 \mathrm{mV}$. This standard internal solution was supplemented with calcium indicators as described in Results. Series resistance was compensated by $75-90 \%$ during recordings, which were made using an Axon Multiclamp 700A amplifier (Axon Instruments, Union City, CA). Data were filtered at $2-5 \mathrm{kHz}$ and sampled at $10 \mathrm{kHz}$. Access resistance and leak currents were monitored continuously, and experiments were rejected if these parameters changed significantly during recording. Flow rates were $1-2 \mathrm{ml} / \mathrm{min}$. Experiments were performed at room temperature.

Parallel fibers were stimulated with brief pulses $(100-300 \mu \mathrm{sec}, 50-$ $500 \mu \mathrm{A}$ ) using a glass theta electrode (World Precision Instruments, Sarasota, FL) filled with saline and positioned in the molecular layer. Bicuculline $(20 \mu \mathrm{M})$ was used to block $\mathrm{GABA}_{\mathrm{A}}$-mediated synaptic currents. Climbing fibers were activated by placing a stimulus electrode in the granule cell layer. Individual climbing fiber responses were identified by a large all-or-none response with a sharp stimulus threshold. In addition to bicuculline (20 $\mu \mathrm{M}), 2,3$-Dioxo-6-nitro-1,2,3,4-tetrahydrobenzo[f] quinoxaline-7-sulfonamide (NBQX) (250-500 nм) was added to reduce climbing fiber EPSCs by $25-75 \%$ (Foster and Regehr, 2002) and to reduce voltage-clamp errors. For experiments measuring DSI, interneurons were stimulated by placing the stimulus electrode in the molecular layer in the presence of $10 \mu \mathrm{M}$ NBQX.
Calibration of calcium indicators. To convert fluorescence ratios to calcium concentrations, we used the relationship:

$$
\mathrm{Ca}_{\mathrm{i}}=K_{\mathrm{D}} \cdot \beta \cdot\left(R-R_{\min }\right) /\left(R_{\max }-R\right),
$$

where $K_{\mathrm{D}}$ is the experimentally measured dissociation constant of the indicator for calcium, $R_{\min }$ and $R_{\max }$ are the fluorescence ratios at 0 and saturating calcium concentrations, respectively, and $\beta$ is defined as the ratio of calcium-free versus calcium-bound fluorescence at the wavelength used as the denominator in $R$ (Grynkiewicz et al., 1985). Because we have chosen the isosbestic point of the indicators for this wavelength, $\beta=1$.

Measurement of indicator dissociation constants $\left(\mathrm{K}_{D}\right)$. Previous studies have shown that the properties of indicators can change both as a result of buffer composition and from cytoplasmic interactions within cells. For example, the $K_{\mathrm{D}}$ of calcium indicators can increase three- to fourfold when loaded into some types of cells (Baylor and Hollingworth, 1988; Konishi et al., 1988; Harkins et al., 1993; Kurebayashi et al., 1993). The extent to which such a $K_{\mathrm{D}}$ shift occurs in Purkinje cells is not known and therefore introduces uncertainty to measurements of $\mathrm{Ca}_{\text {post }}$ within Purkinje cells. We therefore performed experiments to determine the $K_{\mathrm{D}}$ of indicators within Purkinje cells. We began by including BSA $(20 \mathrm{mg} / \mathrm{ml})$ in our internal solution to mimic protein binding that could occur in vivo (Konishi et al., 1988; Harkins et al., 1993).

The $K_{\mathrm{D}}$ of calcium indicators was measured in a spectrofluorimeter (Spex Fluorolog, Edison, NJ). Calibration solutions were prepared according to the technique of Tsien and Pozzan (1989). Briefly, calcium was buffered to known levels with $10 \mathrm{~mm}$ EGTA to which varying amounts of $\mathrm{CaCl}_{2}$ were added. Measurements were made at room temperature in a buffer that consisted of (in mM): $135 \mathrm{CsMeSO}_{4}, 15 \mathrm{CsCl}, 15$ HEPES, and 10 TEA, pH 7.30, which are the same concentrations as in our intracellular recording solution. Several minor components of the intracellular recording solution that could interfere with $K_{\mathrm{D}}$ measurements were omitted from the calibration buffer. EGTA-buffered solutions were used to clamp calcium at concentrations up to $31 \mu \mathrm{M}$. Above the buffering range of EGTA, $\mathrm{CaCl}_{2}$ was added directly to calibration solutions to obtain free calcium concentrations of $0.1-10.0 \mathrm{~mm}$. Fits of the Hill equation to fluorescence values, with the Hill coefficient constrained to 1 , were used to determine $K_{\mathrm{D}}$. The $K_{\mathrm{D}}$ of mag-fura- 5 for magnesium was measured at $3.7 \mathrm{~mm}$.

Addition of BSA to the calibration buffer increased the $K_{\mathrm{D}}$ of several of the calcium indicators. As shown for fura- $2 \mathrm{FF}$ in Figure $1 \mathrm{Aa}$, BSA increased the $K_{\mathrm{D}}$ by fourfold, from 8 to $32 \mu \mathrm{M}$. Similarly, BSA increased the $K_{\mathrm{D}}$ of fura- 2 and mag-fura- 5 by 3.3 -fold and 4.0 -fold, respectively (see Table 1). Although there is uncertainty regarding the cytoplasmic protein concentration in Purkinje cells, the shift that we observe in $K_{\mathrm{D}}$ suggests that the affinity of these indicators may also change when loaded in a Purkinje cell. Because of the possibility of such a shift in affinity, using cuvette $K_{\mathrm{D}}$ values to estimate calcium concentrations with these indicators could cause underestimation of calcium levels by a factor of 3-4.

Fluo-5N, however, is not prone to such large uncertainties. We found that BSA did not significantly alter the affinity of fluo-5N (Fig. 1 $A b$ ), which suggests that the dissociation constant determined in a cuvette is appropriate for quantifying calcium levels within a cell, regardless of the extent to which fluo- $5 \mathrm{~N}$ is bound to protein within the cell. Our measurements of $K_{\mathrm{D}}$ and the effects of BSA are summarized in Table 1.

Magnesium sensitivity of the indicators. For some indicators, sensitivity to magnesium can complicate the quantification of calcium levels. $K_{\mathrm{D}}$ values for magnesium are $5.6 \mathrm{~mm}$ for fura-2 (Grynkiewicz et al., 1985) and $3.7 \mathrm{~mm}$ for mag-fura-5 (our data), whereas fura-2FF does not respond to Mg changes that are $<1 \mathrm{M}$ (Xu-Friedman and Regehr, 1999). Because the fractional changes in $\mathrm{Mg}$ are usually small and the indicators used in this study are much more sensitive to $\mathrm{Ca}$ than to $\mathrm{Mg}$, it is unlikely that small changes in $\mathrm{Mg}$ influence the quantification of calcium levels. However, it is possible that resting levels of magnesium, which are much higher than those of calcium, can influence the resting fluorescence ratio and make it difficult to quantify small changes in calcium with an indicator such as mag-fura-5.

Indicator pairs. The insensitivity of the $K_{\mathrm{D}}$ of fluo- $5 \mathrm{~N}$ to proteins sug- 
$\mathrm{Aa}$

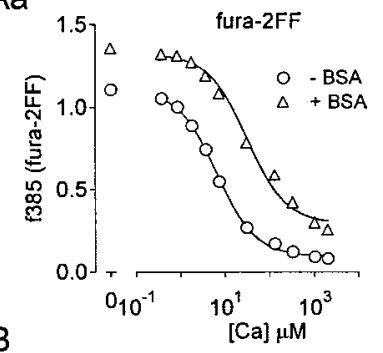

b
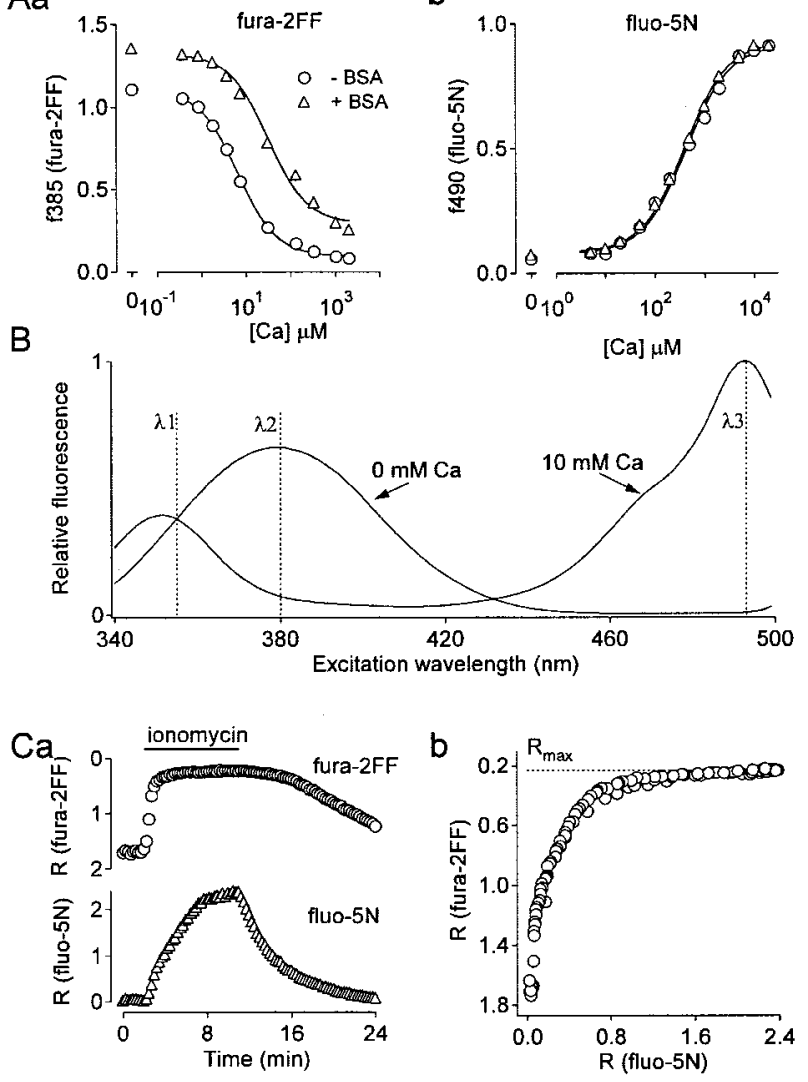

Figure 1. Calibration of calcium indicators. $A$, Calcium dependence of fura-2FF $(A a)$ and fluo- $5 \mathrm{~N}\left(\mathrm{Ab}\right.$ ) fluorescence in the $\mathrm{CSMeSO}_{4}$ calibration buffer in the absence (circles) and presence (triangles) of BSA $(20 \mathrm{mg} / \mathrm{ml})$. BSA increased the $K_{D}$ of fura-2FF from 8 to $32 \mu \mathrm{m}$ but did not alter the $K_{D}$ of fluo-5N. $B$, Fluorescence excitation spectra for a combination of fura-2FF $(500 \mu \mathrm{M})$ and fluo-5N (250 $\mu \mathrm{m})$ measured in a cuvette, measured at $0 \mathrm{~mm} \mathrm{Ca} \mathrm{(6} \mathrm{mm} \mathrm{EGTA)} \mathrm{and} 10 \mathrm{~mm}$ Ca. This dye combination has an isosbestic point of $355 \mathrm{~nm}(\lambda 1)$. Fura-2FF and fluo-5N have peaks at $380 \mathrm{~nm}(\lambda 2)$ and $490 \mathrm{~nm}(\lambda 3)$, respectively. C, In situ measurement of $R_{\max }$ with ionomycin. $C a$, Fluorescence ratios for fura-2FF and fluo-5N were monitored at 15 sec intervals during bath application of ionomycin $(20 \mu \mathrm{M})$ in the presence of $10 \mathrm{~mm}$ Ca. After $10 \mathrm{~min}$ of ionomycin application, 4 mM EGTA with no added calcium or ionomycin was bath applied. Cb, Ratio changes in fura-2FF plotted against ratio changes in fluo-5N. Saturation of fura-2FF was apparent during ionomycin application.

gested a strategy to determine the appropriate calibration parameters for fura-2, fura-2FF, and mag-fura-5. It is possible to estimate calcium levels simultaneously with fluo-5N and one of these UV-excited indicators as illustrated in Figure $1 B$, in which excitation spectra of a combination of fura- $2 \mathrm{FF}$ and fluo- $5 \mathrm{~N}$ are shown. Our goal was to test the accuracy of calibration parameters by comparing simultaneous calcium measurements from two indicators. Using the wavelengths indicated in Figure $1 B$, we calculated the fluorescence ratio of fura- $2 \mathrm{FF}$ as $\lambda 2 / \lambda 1$. We also treated fluo- $5 \mathrm{~N}$ as a ratiometric indicator by calculating its fluorescence ratio as $\lambda 3 / \lambda 1$, using its $490 \mathrm{~nm}$ peak $(\lambda 3)$ and the isosbestic point of fura- $2 \mathrm{FF}$ $(\lambda 1)$. This approach, with slight variations in wavelengths (see Table 1 ), was taken to calculate fluorescence ratios for pairs of indicators in each of the following three combinations (at the indicated concentrations): (1) fluo- $5 \mathrm{~N}$ $(83 \mu \mathrm{M})$ with fura- $2(830 \mu \mathrm{M})$, (2) fluo-5N $(250 \mu \mathrm{M})$ with fura- $2 \mathrm{FF}(500 \mu \mathrm{M})$, and (3) fluo-5N $(250 \mu \mathrm{M})$ with mag-fura-5 $(500 \mu \mathrm{M})$.

For calibration and imaging experiments using indicator pairs, a filter cube containing a $505 \mathrm{~nm}$ dichroic and 515 long-pass emission filter was used. For experiments with either fura- $2 \mathrm{FF}$ or mag-fura- 5 alone, a 455 $\mathrm{nm}$ dichroic and $455 \mathrm{~nm}$ long-pass emission filter were used.

In situ measurement of $\mathrm{R}_{\max }$. We first used this approach of measuring calcium with a pair of indicators to make in situ measurements of the calibration parameter $R_{\max }$ for fura-2, fura- $2 \mathrm{FF}$, and mag-fura- 5 directly
Table 1. Summary of indicator properties

\begin{tabular}{lllll}
\hline Indicator & $\lambda(\mathrm{nM})$ & $K_{\mathrm{D}}$ & $\Delta K_{\mathrm{D}}$ (BSA/Cuv) & $\Delta R_{\max }$ (iono) \% \\
\hline Fura-2 & 361,380 & $131 \mathrm{nM}$ & 3.3 & 12 \\
Fura-2FF & 355,380 & $7.7 \mu \mathrm{M}$ & 4.0 & 16 \\
Mag-fura-5 & 349,384 & $38 \mu \mathrm{M}$ & 4.0 & 28 \\
Fluo-5N & 490 & $410 \mu \mathrm{M}$ & 1.0 & \\
\hline
\end{tabular}

Indicated wavelengths $(\lambda)$ were used to excite calcium indicators. $K_{D}$ was measured in our intracellular solution. $\Delta K_{D}$ indicates relative change of $K_{D}$ in the presence of $20 \mathrm{mg} / \mathrm{ml} \mathrm{BSA} . \Delta R_{\max }$ indicates the percentage change in $R_{\max }$ measured in situ compared with cuvette values.

in Purkinje cell dendrites. This parameter is subject to change when indicators are introduced into a cell. As calcium levels become sufficiently high to cause the ratio to approach $R_{\max }$ (the fluorescence ratio at saturating $\left.\mathrm{Ca}_{\text {post }}\right)$, measurements of $\mathrm{Ca}_{\text {post }}$ become extremely sensitive to $R_{\max }$. Hence, errors in measuring $R_{\max }$ greatly distort measurements of calcium at concentrations above the $K_{\mathrm{D}}$ of the indicator. To measure $R_{\max }$ in situ, we elevated calcium in the cell by bath applying the calcium ionophore ionomycin (Erdahl et al., 1995; Wang et al., 1998) in the presence of $10 \mathrm{~mm}$ calcium (Fig. 1C). By comparing fluorescence ratios of fura- $2 \mathrm{FF}$ and fluo- $5 \mathrm{~N}$ (Fig. $1 \mathrm{Ca}, \mathrm{Cb}$ ), it is apparent that the plateau of the fura- $2 \mathrm{FF}$ fluorescence ratio indicates that the indicator is saturated, because the fluorescence ratio of the lower-affinity fluo- $5 \mathrm{~N}$ continues to increase, indicating that calcium continues to rise. These results indicate that the fluorescence ratio of fura- $2 \mathrm{FF}$ has reached its maximum, thereby providing us with an in situ measurement of $R_{\max }$. In this manner, using fluo- $5 \mathrm{~N}$ to verify that the higher-affinity indicator reached saturation, we measured $\mathrm{R}_{\max }$ in situ for fura-2, fura-2FF, and mag-fura-5.

It was not possible to elevate calcium levels within cells sufficiently to saturate the fluo- $5 \mathrm{~N}$ response and directly measure $R_{\max }$ for this indicator. However, fluo-5N has such a low affinity (Table 1) that calcium levels in our experiments do not lead to ratio changes that approach $R_{\max }$ for fluo-5N, and as a result slight changes in $R_{\max }$ have minor effects on $\mathrm{Ca}_{\text {post }}$ measurements with fluo- $5 \mathrm{~N}$. We therefore used cuvette values of $R_{\max }$ to convert fluo- $5 \mathrm{~N}$ fluorescence to calcium concentrations.

We also estimated the calibration parameter $R_{\min }$ within cells by bath applying ionomycin in the presence of $\sim 10 \mathrm{~nm}$ external calcium $(4 \mathrm{~mm}$ EGTA with no added Ca). We found that changes in $R_{\min }$ from loading in cells were small. Moreover, estimates of the large calcium levels required to evoke endocannabinoid release were not highly sensitive to $R_{\min }$.

Cuvette measurements of $R_{\min }$ and $R_{\max }$ were made using the experimental imaging system with a $30 \mu \mathrm{M}$ path length cuvette placed on the stage of the microscope. Our standard cesium intracellular solution was supplemented with indicators. $R_{\min }$ was measured in the presence of 6 mM EGTA and no added calcium. $R_{\max }$ was measured with $10 \mathrm{~mm} \mathrm{CaCl}{ }_{2}$.

For measuring cellular calcium transients with fura-2, fura-2FF, and mag-fura-5, we used the $R_{\min }$ value obtained in a cuvette and the $R_{\max }$ value obtained in situ. Because we could not experimentally verify that fluo-5N was saturating during ionomycin application, cuvette values of $R_{\min }$ and $R_{\max }$ were used.

Cellular imaging. Imaging was conducted using a Cooke Sensicam QE mounted on an Olympus BX51 upright microscope equipped with a $60 \times, 0.9$ numerical aperture objective. The imaging protocols for measurement of calcium transients evoked by voltage steps consisted of sets of three images (20 msec exposure) acquired in succession at the three appropriate excitation wavelengths $(\lambda 1, \lambda 2, \lambda 3)$ (Fig. $1 B$, Table 1$)$ using a rapid wavelength switching monochromator (Till Photonics, Grafelfing, Germany). Groups of three images were collected every $250 \mathrm{msec}$ for $10 \mathrm{sec}$. There was a $6 \mathrm{msec}$ delay between successive images at each time point. The voltage step began after $1 \mathrm{sec}$ of imaging. Fluorescence excitation was restricted to a small area including the Purkinje cell dendrites and an adjacent cell-free region that was used for background correction. Care was taken to exclude the soma from the area of excitation. Photobleaching of indicators during imaging protocols was $<1 \%$. Data analysis was performed with Vision Software (Till Photonics) and Igor (Wavemetrics, Lake Oswego, OR).

Calcium indicators were obtained from Molecular Probes (Eugene, $\mathrm{OR}$ ) with the exception of fura-2FF, which was from Teflabs (Austin, 
A
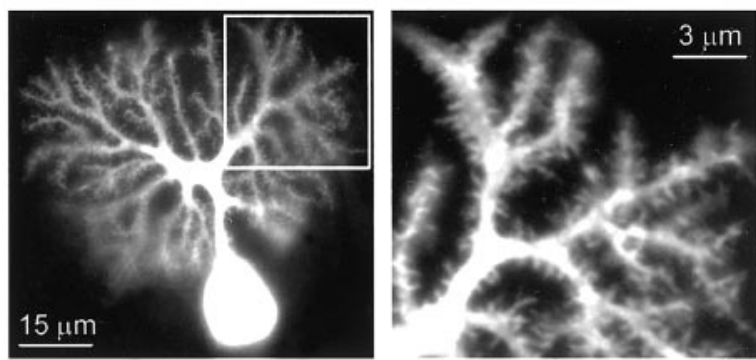

B
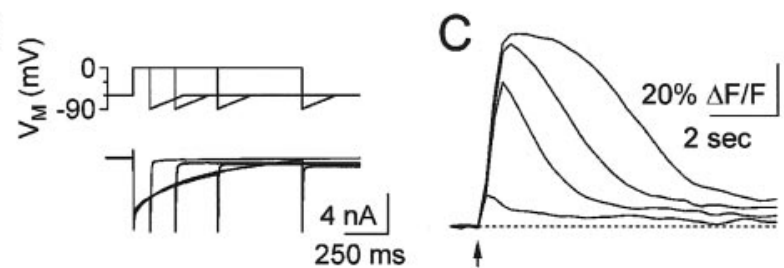

Figure 2. Graded calcium transients in cerebellar Purkinje cells. $A$, Purkinje cell from a P10 rat in a sagittal slice. The cell was loaded with fura- $2 \mathrm{FF}$ and excited at $380 \mathrm{~nm}$. B, Top, Voltage steps from -60 to $0 \mathrm{mV}$ were delivered for a duration of $100-1000 \mathrm{msec}$, followed by a 200 msec ramp from -90 to $-60 \mathrm{mV}$. Bottom, Calcium currents recorded in the presence of intracellular Cs, TEA, and QX-314. C, Graded fluorescence transients were produced by voltage steps from $B$, delivered at the time indicated by the arrow, with the largest transients corresponding to the longest depolarizations. A region selected from the image in $A$ (right) was used for analysis. Exposures were obtained at 250 msec intervals.

TX). Ionomycin was from Molecular Probes. NBQX was from Tocris (Ellisville, MO), and bicuculline was from Sigma (St. Louis, MO).

\section{Results}

Our strategy for determining the calcium sensitivity of retrograde inhibition was to combine calcium measurements with voltageclamp recordings of synaptic responses to quantify the relationship between postsynaptic calcium levels and retrograde endocannabinoid inhibition. This approach required two preliminary steps. First we needed to establish recording conditions for controlled elevation of calcium. This is difficult because Purkinje cell dendrites tend to fire calcium action potentials, which result in large calcium transients that do not depend on the length of the depolarization. Second, we needed to quantify postsynaptic calcium levels. Although there have been many studies of calcium signaling in Purkinje cells (Ross and Werman, 1987; Tank et al., 1988; Khodakhah and Armstrong, 1997; Finch and Augustine, 1998; Takechi et al., 1998; Wang et al., 2000), we needed to develop methods to determine absolute levels of calcium before we could ultimately determine the calcium dependence of retrograde signaling by endocannabinoids.

\section{Using voltage steps to produce graded calcium transients}

Our first goal was to control calcium influx. We took several steps to achieve voltage control sufficient to prevent spiking and permit regulation of the duration of calcium currents. First, we used a cesium-based internal solution with added TEA and QX-314 to block potassium and sodium channels. Second, we recorded from Purkinje cells from postnatal day (P) 10-P12 rats, which have electrically compact dendritic trees. The size of the dendritic arbor of the Purkinje cells used in this study is indicated by the fluorescence image of a cell loaded with the calcium-indicator fura-2FF (Fig. 2A). It was difficult to control calcium entry into Purkinje cells from animals older than P12, because brief depolarizations evoked dendritic calcium spikes. Finally, delivery of a
$200 \mathrm{msec}$ voltage ramp from -90 to $-60 \mathrm{mV}$ after the voltage step helped to suppress spiking (Fig. $2 B$, top). Under these conditions, voltage steps generally did not produce dendritic spikes and uncontrolled calcium entry (Fig. 2B, bottom). Recordings were terminated if cells spiked during voltage steps. Calcium transients were measured in dendritic regions selected from Figure $2 A$ (right) and are shown here as $\Delta F / F$ (Fig. 2C). The amplitudes of calcium transients were graded, progressively increasing with the duration of the voltage step. These recording methods were used in subsequent experiments for indicator calibration and measurements of retrograde inhibition.

\section{Quantification of dendritic calcium transients in Purkinje cells}

We addressed two issues to quantify calcium levels with fluorometric indicators. First, we needed to select an indicator with appropriate calcium sensitivity. If the affinity were too high, the indicator would become saturated during calcium transients and it would not provide accurate estimates of $\mathrm{Ca}_{\text {post }}$. If the affinity were too low, the indicator would have poor sensitivity. A second issue is that the properties of indicators can change both as a result of buffer composition and from cytoplasmic interactions within cells (Konishi et al., 1988; Harkins et al., 1993; Kurebayashi et al., 1993). Therefore we could not rely exclusively on in vitro calibrations, and we needed to determine the properties of the indicators within Purkinje cells.

As described in Materials and Methods, several steps were taken to address these concerns. Indicators were chosen for calibration on the basis of their affinities and spectral properties (Table 1). We selected three ratiometric indicators (fura-2, fura2FF, and mag-fura-5) that can be calibrated using Equation 1 (Grynkiewicz et al., 1985). These indicators have very similar excitation peaks in the UV portion of the spectrum and similar emission peaks. However, they differ in their calcium affinities (131 nM, $7.7 \mu \mathrm{M}, 38 \mu \mathrm{M}$, respectively, in our internal solution) and therefore are suited to measuring calcium over different concentration ranges. We also used fluo-5N, a single-wavelength dye, to evaluate the three ratiometric indicators. Fluo- $5 \mathrm{~N}$ has several useful properties. First, its extremely low affinity for calcium $\left(K_{\mathrm{D}}=410 \mu \mathrm{M}\right)$ makes it unlikely to become saturated during dendritic calcium transients. Second, in cuvette experiments (see Materials and Methods) we found that protein binding did not significantly alter the affinity of fluo-5N (Fig. $1 A b$ ), which suggests that the dissociation constant determined in a cuvette is appropriate for quantifying calcium levels within a cell, regardless of the extent to which fluo- $5 \mathrm{~N}$ is bound to protein. Finally, its spectral properties (excitation peak at $490 \mathrm{~nm}$ ) allow it to be loaded simultaneously with the other indicators but excited independently. This allowed us to use fluo-5N to evaluate fura-2, fura2-FF, and mag-fura-2 by comparing independent measurements obtained from pairs of indicators (fura- $2 /$ fluo- $5 \mathrm{~N}$, fura2FF/fluo-5N, and mag-fura-5/fluo-5N), as shown in Figure 3.

Experiments in which Purkinje cells were loaded with fura-2 and fluo- $5 \mathrm{~N}$ revealed that the affinity of fura- 2 is too high for our purposes. Fluorescence ratios for both indicators were measured simultaneously during a series of voltage steps of 50-1000 msec (Fig. $3 A a, A b$ ). Fura-2 exhibited nonsaturating ratio changes during voltage steps of 50 or $100 \mathrm{msec}$ duration (Fig. $3 A a$, gray traces), but because of its high affinity for calcium $\left(K_{\mathrm{D}}=131 \mathrm{nM}\right)$, fura-2 saturated completely during voltage-step durations of 250-1000 msec (Fig. 3Aa). Fluo-5N, because of its low affinity for calcium $\left(K_{\mathrm{D}}=410 \mu \mathrm{M}\right)$, did not exhibit a detectable fluorescence change during voltage steps of 50-100 msec (Fig. 3Ab, gray trac- 

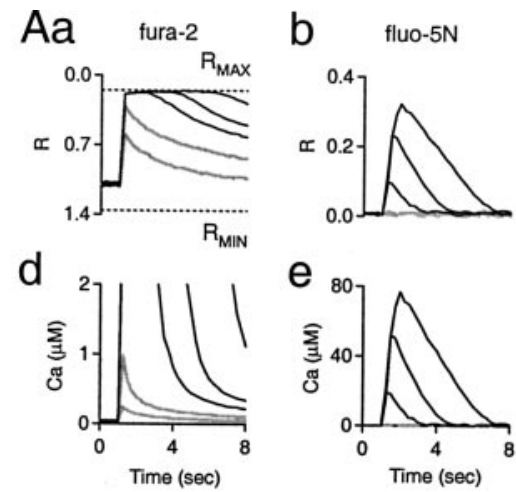

C
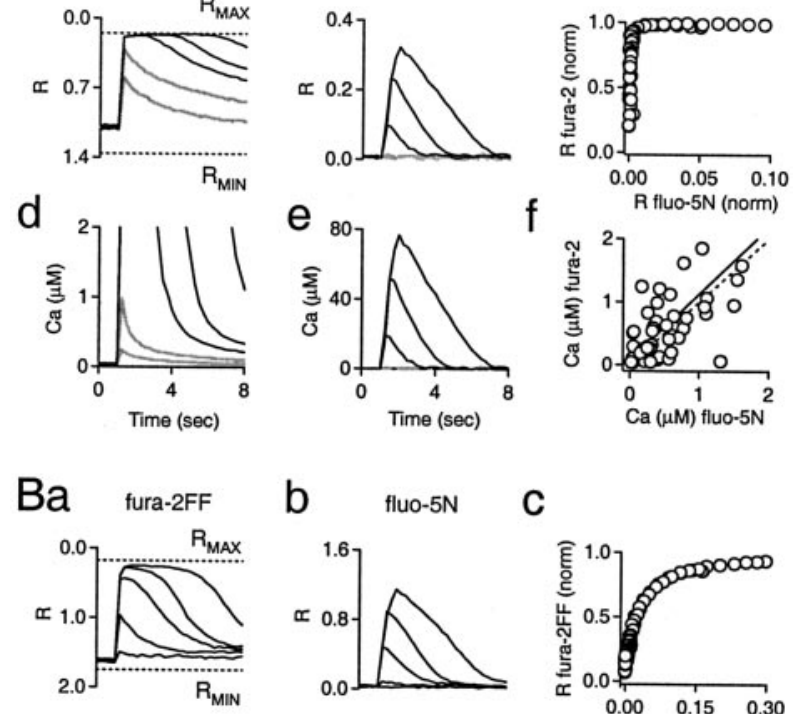

b

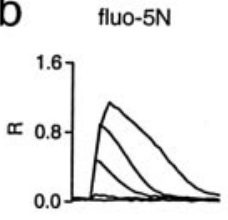

C
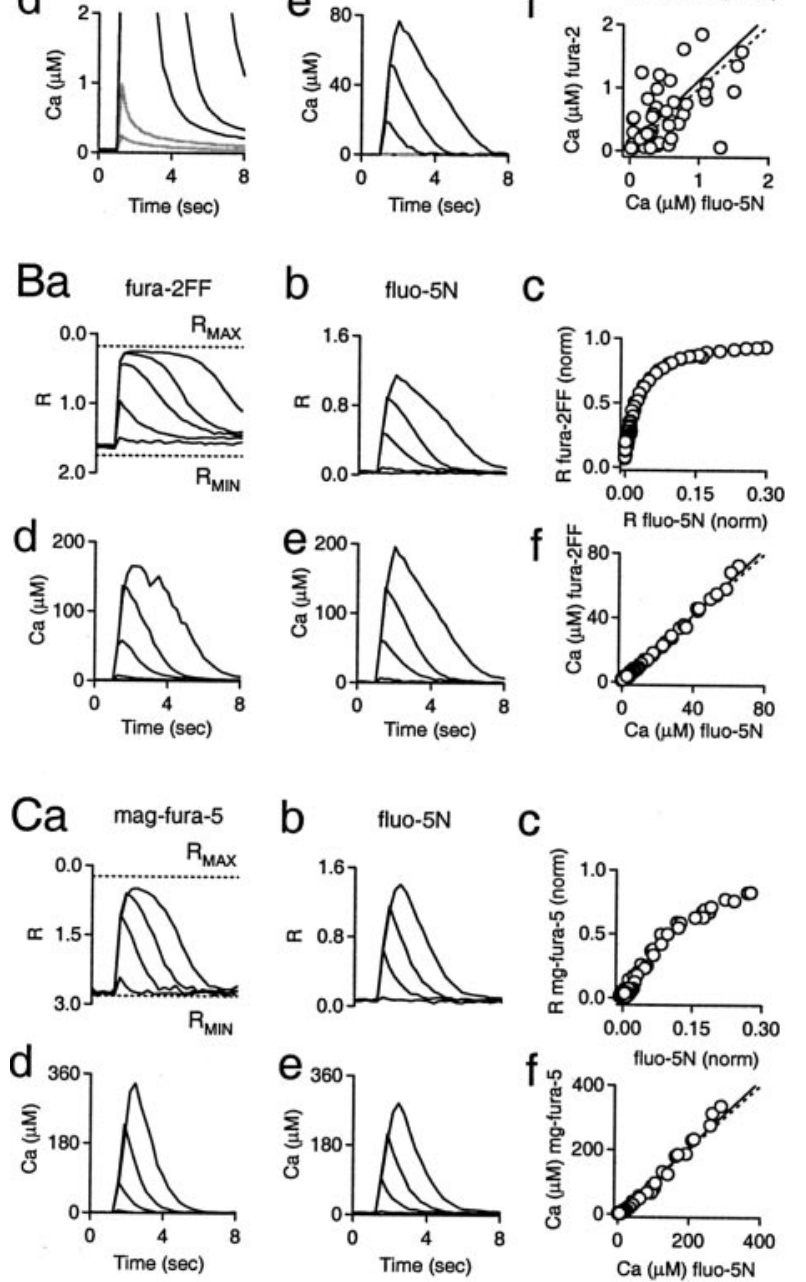

Figure 3. Quantification of dendritic calcium transients. Purkinje cells were loaded with different indicator pairs, fura-2/fluo- $5 \mathrm{~N}(A)$, fura-2FF/fluo- $5 \mathrm{~N}(B)$, and mag-fura-5/fluo- $5 \mathrm{~N}$ (C). Fluorescence transients produced by a series of voltage steps were then measured simultaneously for each pair of indicators. Fluorescence ratios are plotted for fura-2, fura-2FF, or mag-fura- 5 in $a$, and $R_{\min }$ and $R_{\max }$ are indicated in with dotted line. Fluorescence ratios for fluo- $5 \mathrm{~N}$ are plotted in $b$. Ratios determined with indicator pairs are compared in $c$, where ratios were normalized so that $R_{\min }=0$ and $R_{\max }=1$. In $d$ and e, calcium values were then calculated from the traces in $a$ and $b$, respectively, using the using calibration parameters described in Materials and Methods. In $f$ the values of calcium determined for each of a pair of indicators are plotted for the purpose of comparison. A line with a slope of 1 is indicated with dotted lines, and regressions of the data points are indicated with solid lines with slopes of 1.06 for $A f, 1.02$ for $B f$, and 1.04 for $(f$. In $A$ and $B$, voltage steps $(50,100,250,500,1000 \mathrm{msec})$ were delivered, and in $C$, the 50 msec voltage step was omitted. In $A a, A b, A d$, and $A e$, gray traces correspond to 50 and 100 msec depolarizations. In Ae and $A f$, calcium concentrations calculated from fura-2 fluorescence ratios that exceeded $2 \mu \mathrm{m}$ were not displayed. Points corresponding to calculated values of $\mathrm{Ca}_{\text {post }}>77 \mu \mathrm{M}$ (10 times the $K_{D}$ of fura-2FF) or $380 \mu \mathrm{m}$ (10 times the $K_{D}$ of mag-fura-5) were not displayed in $B f$ and $C f$, respectively.

es). Comparison of the normalized ratio changes indicates that fura-2 saturates completely with calcium signals that cause a $<1 \%$ change in the fluorescence ratio of fluo-5N (Fig. 3Ac). Fluorescence ratios from fura- 2 and fluo- $5 \mathrm{~N}$ were converted to cal- cium concentrations (Fig. 3Ad,Ae). Calcium measurements from these two indicators are difficult to compare because their dissociation constants differ by a factor of several thousand (Fig. 3Af). It is apparent, however, that fura-2 readily saturates and is not suitable for measuring dendritic calcium transients during voltage steps $>100 \mathrm{msec}$.

Similar experiments revealed that fura-2FF is well suited to measuring the $\mathrm{Ca}_{\text {post }}$ transients that produce retrograde inhibition. Fluorescence ratios obtained during voltage steps of 50$1000 \mathrm{msec}$ are shown for fura-2FF (Fig. 3Ba) and fluo-5N (Fig. $3 B b)$. The plot of the fluorescence ratio of fura- $2 \mathrm{FF}$ versus the ratio of fluo- $5 \mathrm{~N}$ shows that there is some saturation of the fura2FF response during calcium transients that cause large fluorescence signals in fluo-5N (Fig. $3 B c$ ). We then compared the calcium concentrations estimated with fura-2FF (Fig. $3 B d$ ) and fluo-5N (Fig. 3Be). Because peak calcium levels during long voltage steps saturated fura-2FF (Fig. $3 B a, B c$ ), we discarded calcium measurements that exceeded $77 \mu \mathrm{M}\left(10\right.$-fold above the $K_{\mathrm{D}}$ of fura-2FF). In this concentration range, calcium measurements made with fura-2FF and fluo-5N were in close agreement (Fig. $3 B f$ ), as indicated by the linear regression of fura-2FF calcium values versus fluo- $5 \mathrm{~N}$ calcium values, which had a slope of 1.03. In a group of eight cells that were loaded with fura-2FF and fluo- $5 \mathrm{~N}$, the slope of this regression was $0.99 \pm 0.03$. We conclude that fura- $2 \mathrm{FF}$ and fluo- $5 \mathrm{~N}$ report calcium concentrations that are in agreement up to $\sim 80 \mu \mathrm{M}$.

Similar experiments suggested that mag-fura- 5 is also suitable for quantifying calcium levels arising from Purkinje cell depolarization (Fig. 3C). After conversion of fluorescence ratios (Fig. $3 \mathrm{Ca}, \mathrm{Cb}$ ) to calcium concentrations (Fig. $3 \mathrm{Cd}, \mathrm{Ce}$ ), we compared calcium estimates obtained with mag-fura- 5 and fluo- $5 \mathrm{~N}$, considering values up to 10 -fold greater than the $K_{\mathrm{D}}$ of mag-fura-5, or $380 \mu \mathrm{M}$. Because of its low affinity $\left(K_{\mathrm{D}}=38 \mu \mathrm{M}\right)$, mag-fura-5 does not saturate during calcium transients that cause large fluorescence changes in fluo-5N (Fig. 3Cc). For the cell shown in Figure $3 C$, the slope of the linear regression of calcium concentrations measured with fluo- $5 \mathrm{~N}$ versus mag-fura- 5 had a slope of 1.04 (Fig. 3Cf). For a group of 10 cells examined in this manner, the slope of a regression of calcium measurements from magfura-5 versus fluo- $5 \mathrm{~N}$ was $1.02 \pm 0.03$. We conclude that measurements of calcium with mag-fura- 5 and fluo- $5 \mathrm{~N}$ are in agreement at concentrations up to $380 \mu \mathrm{M}$. Moreover, despite its sensitivity to magnesium (see Materials and Methods), magfura- 5 appears to be a suitable indicator for measuring calcium transients in Purkinje cells.

On the basis of these experiments, we conclude that fura- $2 \mathrm{FF}$ and mag-fura- 5 are suitable for measuring absolute calcium concentrations during depolarization of Purkinje cells. This conclusion rests on the close agreement of these two indicators with fluo- $5 \mathrm{~N}$ when the indicators were simultaneously loaded and imaged. On the basis of its fivefold lower $K_{\mathrm{D}}$, fura-2FF is better suited to the smaller calcium levels produced by brief depolarizations. Fura-2, however, readily saturates during brief depolarizations, and because of its high affinity it could not resolve calcium transients during depolarizations $>100 \mathrm{msec}$. The agreement between the simultaneously loaded indicators suggests that despite the shift in $K_{\mathrm{D}}$ seen for fura-2FF and mag-fura- 5 caused by addition of BSA (Fig. 1, Table 1), such a shift does not occur in the cell. If we had been unable to determine the $K_{\mathrm{D}}$ values of these indicators within Purkinje cells, our estimates of $\mathrm{Ca}_{\text {post }}$ on the basis of in vitro $K_{\mathrm{D}}$ values would be lower bounds subject to the uncertainty of the extent to which the $K_{\mathrm{D}}$ shifted to higher values within cells. Also, the linear relation between calcium measurements 
obtained with the simultaneously loaded dyes indicates that the experiments with ionomycin provide an accurate measurement of $R_{\max }$. For subsequent experiments that measured the calcium dependence of retrograde inhibition, we used a single calibrated indicator, either fura-2FF or mag-fura-5, to minimize the duration of fluorescence excitation and bleaching.

\section{Ca $a_{\text {post }}$ dependence of DSE}

We next combined synaptic recordings with calcium imaging to determine the relationship between peak dendritic $\mathrm{Ca}_{\text {post }}$ and the extent of retrograde inhibition by endocannabinoids at synapses onto Purkinje cells. Our experimental approach was to deliver a series of voltage steps to the Purkinje cell to elevate $\mathrm{Ca}_{\text {post }}$ to different levels and then determine the relationship between $\mathrm{Ca}_{\text {post }}$ and the resulting synaptic inhibition. Recent studies have suggested that metabotropic receptor activation may modulate the calcium dependence of cannabinoid release or even evoke calcium-independent cannabinoid release (Maejima et al., 2001; Ohno-Shosaku et al., 2001; Varma et al., 2001; Kim et al., 2002; Doherty and Dingledine, 2003). Here we focus on the calciumdependent release of endocannabinoids in the absence of metabotropic receptor activation at $\mathrm{CF}, \mathrm{PF}$, and inhibitory synapses onto Purkinje cells.

\section{Parallel fiber DSE}

We first examined DSE at the parallel fiber to Purkinje cell synapse (Fig. 4). Each Purkinje cell receives inputs from thousands of parallel fibers that form synapses onto distal portions of its dendrites (Palay and Chan-Palay, 1974). Parallel fiber synapses were stimulated by placing a stimulus electrode in the molecular layer. PF EPSCs were evoked at $0.5 \mathrm{~Hz}$, allowing us to monitor the onset and recovery of DSE after depolarizations. Short-term facilitation, the predominant form of plasticity at this synapse, decays with a time course of $200 \mathrm{msec}$ and does not alter the amplitude of EPSCs evoked at this stimulus rate (Atluri and Regehr, 1996). In this initial series of experiments, Purkinje cells were loaded with fura-2FF. Calcium transients resulting from voltage steps of $100-$ $1000 \mathrm{msec}$ were imaged in distal portions of Purkinje cell dendrites in the region close to the stimulus electrode (Fig. 4A). Fluorescence ratios obtained from fura-2FF were converted to $\mathrm{Ca}_{\text {post }}$ using the calibration parameters described previously. After 10 stimuli to measure a stable baseline EPSC amplitude, voltage steps of varying durations were delivered to evoke DSE (Fig. $4 B$ ). Parallel fiber stimulation resumed $1 \mathrm{sec}$ after the end of the voltage step. Inhibition of parallel fiber EPSCs was maximal at 3-7 sec after the voltage step (Fig. $4 B$, top panel, vertical dashed lines). To quantify DSE, we averaged three EPSCs preceding the depolarization ("pre") and three EPSCs evoked 3-7 sec after the depolarization ("post"). In addition, three EPSCs were averaged at 55-59 sec after the depolarization ("rec") (Fig. 4B, bottom panel). Peak DSE was defined as $1-$ (post/pre) and ranges from 0 (no inhibition) to 1 (complete inhibition of EPSCs). Depolarizations ranging from 100 to $1000 \mathrm{msec}$ evoked progressively larger dendritic calcium transients (Fig. $4 A$ ) and greater amounts of DSE (Fig. $4 B$ ). From each depolarization trial we obtained a value of peak $\mathrm{Ca}_{\text {post }}$ and a corresponding value of peak parallel fiber DSE. By repeating this protocol with varying durations of depolarization, we were able to plot the relationship between peak DSE and $\mathrm{Ca}_{\text {post }}$ for a single cell (Fig. 4C). By fitting the data points obtained in this manner to the Hill equation, we determined the $\mathrm{Ca}_{\text {post }}$ that produces half-maximal DSE $\left(\mathrm{Ca}_{0.5}\right)$ and the Hill coefficient that describes the cooperativity of the relationship
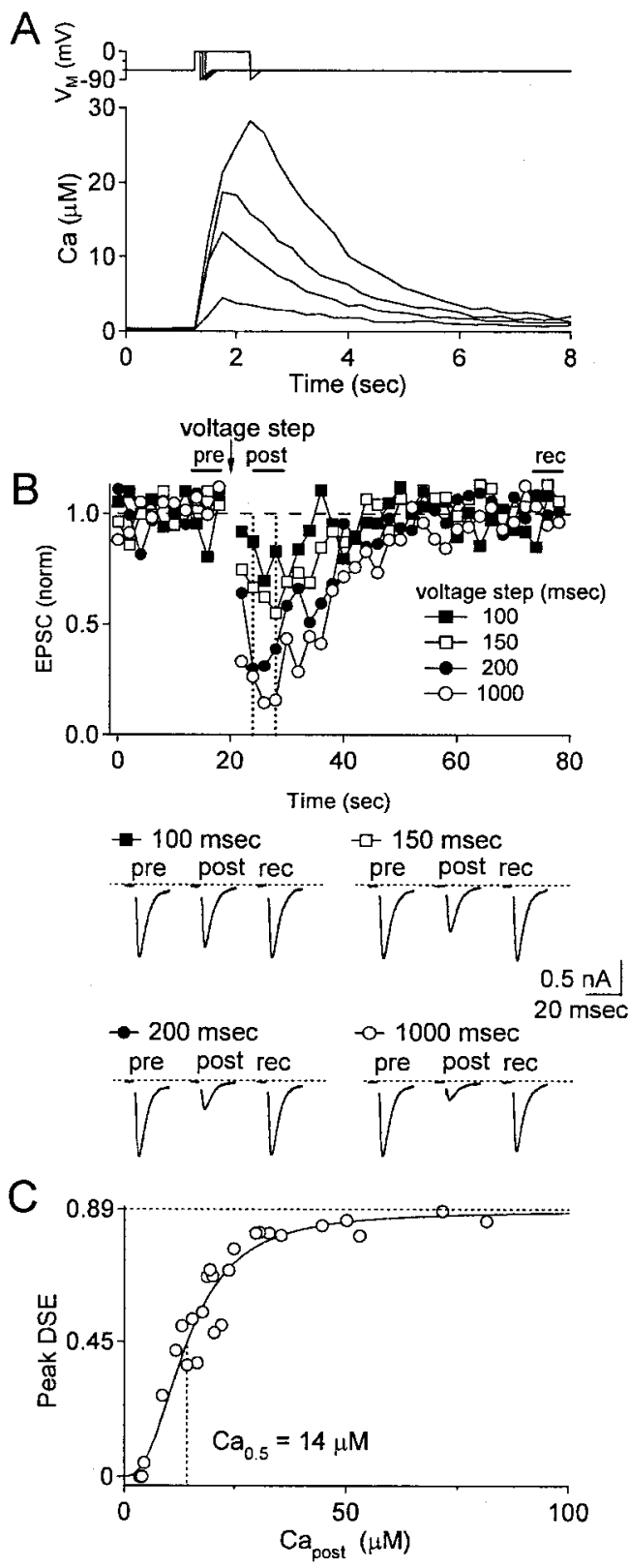

Figure 4. Calcium dependence of DSE at the parallel fiber to Purkinje cell synapse. A, DSE of parallel fiber EPSCs was measured after voltage steps of 100-1000 msec delivered to a Purkinje cell loaded with fura-2FF. Voltage steps (top) and resulting calcium transients (bottom) are imaged in the dendritic region of parallel fiber stimulation. $B$, DSE was evoked by a voltage step delivered after the 10th parallel fiber stimulus (top). Traces are averages of three EPSCs at the indicated time (pre, post, rec). C, Peak DSE was calculated as $1-\left(\right.$ EPSC $_{\text {post }} /$ EPSC $\left._{\text {pre }}\right)$ and plotted versus $\mathrm{Ca}_{\text {post }}$. DSE was half-maximal at $\mathrm{Ca}_{\text {post }}=14 \mu \mathrm{m}$, and the Hill coefficient was 2.5.

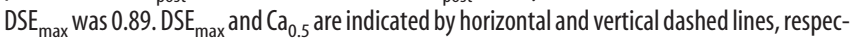
tively. Data in A-C were obtained from one cell.

between $\mathrm{Ca}_{\text {post }}$ and DSE. For the cell shown in Figure $4, \mathrm{Ca}_{0.5}$ was $14.2 \mu \mathrm{M}$, and the Hill coefficient was 2.5.

To determine the calcium dependence of PF DSE, this experimental approach was repeated on five neurons loaded with fura2FF. The relation between peak $\mathrm{Ca}_{\text {post }}$ and peak DSE is shown in Figure $5 A$. Maximum DSE (DSE max $_{\text {) }}$ ) after long voltage steps was $0.89 \pm 0.02$. Fits of the Hill equation have been made to data from each cell. For clarity, DSE values were normalized to the maximum DSE obtained in each cell so that data range between 0 and 

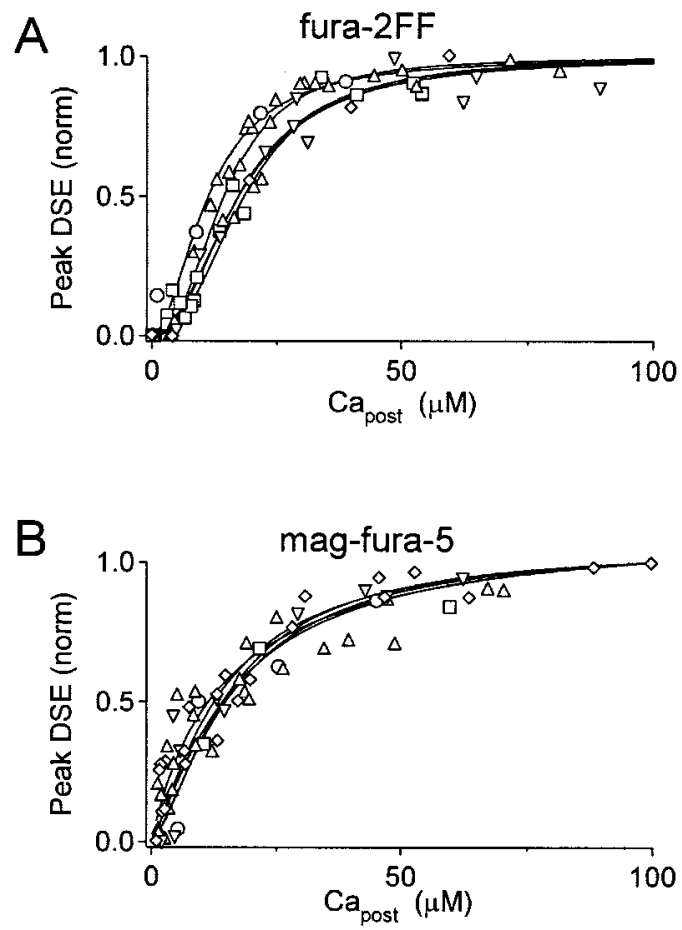

Figure 5. Summary of calcium dependence of parallel fiber DSE. A, Data from five cells loaded with fura-2FF. For clarity, peak DSE values from each cell were normalized. Each cell is represented by a different plot symbol. Fits of the Hill equation to the data points from each cell are superimposed. For five cells, half-maximal DSE occurred at peak $\mathrm{Ca}_{\text {post }}=15.3 \pm 1.1 \mu \mathrm{m}$ cooperativity was $2.3 \pm 0.2$, and peak DSE was $0.89 \pm 0.02$. B, Data from five cells loaded with mag-fura-5. Half-maximal DSE occurred at peak $\mathrm{Ca}_{\text {post }}=17.4 \pm 1.0 \mu \mathrm{m}$, cooperativity was $1.2 \pm 0.10$, and DSE $E_{\max }$ was $0.91 \pm 0.02$.

1. For these experiments, $\mathrm{Ca}_{0.5}=15.3 \pm 1.1 \mu \mathrm{M}$, and the Hill coefficient was $2.3 \pm 0.2$.

To confirm these measurements of the calcium dependence and cooperativity of PF DSE, we performed further experiments using a different calcium indicator, mag-fura-5. Using the same experimental technique as illustrated in Figure 4, we measured the relationship between $\mathrm{Ca}_{\text {post }}$ and PF DSE in five neurons using mag-fura-5 to measure $\mathrm{Ca}_{\text {post }}$ (Fig. $5 B$ ). In these cells, $\mathrm{Ca}_{0.5}=$ $17.4 \pm 1.0 \mu \mathrm{M}$, and the Hill coefficient was $1.2 \pm 0.1$ DSE $_{\max }$ was $0.91 \pm 0.02$. Measurements of $\mathrm{Ca}_{0.5}$ obtained with fura-2FF and mag-fura- 5 for DSE at the parallel fiber synapse are statistically indistinguishable ( $p=0.36$; $t$ test); however, estimates of the Hill coefficient obtained with fura-2FF and mag-fura-5 differed $(p<$ $0.01, t$ test). The lower estimate of cooperativity obtained with mag-fura-5 may result from the difficulty of resolving small calcium transients, less than one-tenth of the $K_{\mathrm{D}}$ of mag-fura-5 $(<\sim 4 \mu \mathrm{M})$, which are critical for accurately measuring cooperativity. Fura-2FF on the other hand was able to resolve these small calcium signals and reported a higher degree of cooperativity in the relationship between postsynaptic $\mathrm{Ca}_{\text {post }}$ and parallel fiber DSE.

\section{Climbing fiber DSE}

We next determined whether the calcium dependence of DSE was similar at the other excitatory synapse onto Purkinje cells, the climbing fiber synapse (Fig. 6). Purkinje cells receive a single powerful climbing fiber synapse that consists of hundreds of release sites located in proximal regions of Purkinje cell dendrites (Palay and Chan-Palay, 1974; Xu-Friedman et al., 2001). Climb- ing fiber synapses are subject to inhibition by endocannabinoids (Kreitzer and Regehr, 2001b). We determined the calcium dependence of CF DSE using an approach that was similar to that used for PF DSE, but with slight modifications to take into account distinct properties of the synapses. Because prominent synaptic depression is observed with repetitive stimulation of $\mathrm{CF}$ synapses (Eccles et al., 1966), we stimulated the CF synapse at 30 sec intervals to allow full recovery from depression between successive EPSCs. This enabled us to measure inhibition of CF EPSCs that resulted from retrograde endocannabinoid inhibition and not from other forms of short-term plasticity such as vesicle depletion. Voltage steps were delivered to voltage-clamped Purkinje cells loaded with fura-2FF, and resulting calcium transients were imaged in proximal dendritic regions corresponding to the location of climbing fiber synapses (Fig. 6A). The voltage step was timed to precede the test stimulus by $5 \mathrm{sec}$ (Fig. $6 B$, top). Voltage steps of 200-2000 msec produced progressively greater $\mathrm{Ca}_{\text {post }}$ and greater inhibition of CF EPSCs (Fig. $6 \mathrm{~B}$, bottom). We determined the baseline EPSC amplitude averaging the three EPSCs preceding the voltage step (pre) and used the EPSC after the voltage step (post) to quantify CF DSE as $1-$ (post/pre).

To determine the relationship between peak $\mathrm{Ca}_{\text {post }}$ and DSE for climbing fiber synapses, we repeated this protocol of delivering voltage steps and measuring $\mathrm{Ca}_{\text {post }}$ and DSE (Fig. 6C). For the neuron shown in Figure $6 A-C$, half-maximal DSE occurred at $\mathrm{Ca}_{\text {post }}=16.0 \mu \mathrm{M}$, and the Hill coefficient was 2.6. This procedure was repeated on six neurons (Fig. 6D). Each cell is indicated with a different plot symbol. For these cells, DSE at the climbing fiber synapse was half-maximal at $\mathrm{Ca}_{\text {post }}=18.5 \pm 0.7$ and had a Hill coefficient of $2.0 \pm 0.2$. The values of $\mathrm{Ca}_{0.5}$ and the Hill coefficient at $\mathrm{CF}$ synapses are very similar to those described above for PF synapses. DSE $\mathrm{max}_{\max }$ at the climbing fiber synapse was $0.47 \pm 0.08$. This value is roughly half of the maximum DSE observed at parallel fiber synapses. Thus DSE at CF and PF synapses shows a similar low sensitivity to $\mathrm{Ca}_{\text {post }}$ and high cooperativity, although the maximal extent of endocannabinoid inhibition is less at CF compared with PF synapses.

\section{Calcium dependence of DSI}

Thus far we have seen that extremely high levels of calcium are required for DSE, almost 100 times as large as has been reported previously for DSI. This raises the question of whether there are large differences in the calcium levels needed to produce retrograde suppression of excitatory and inhibitory synapses or whether previous studies may have underestimated the calcium levels required for DSI. We therefore determined the $\mathrm{Ca}_{\text {post }}$ dependence of DSI.

Purkinje cells receive inhibitory synaptic inputs from stellate and basket cells that are located in the molecular layer of the cerebellum (Palay and Chan-Palay, 1974) and are sensitive to inhibition by endocannabinoids. Previous studies of cerebellar DSI have shown that endocannabinoids inhibit transmitter release from inhibitory nerve terminals by modulating presynaptic calcium channels (Kreitzer and Regehr, 2001a; Diana et al., 2002), altering miniature IPSC frequency (Takahashi and Linden, 2000) and reducing spontaneous firing of interneurons (Kreitzer et al., 2002). To facilitate comparison between different synapses, we determined the calcium dependence of DSI using techniques similar to those used for measurement of CF and PF DSE.

In contrast to the stereotypical localization of excitatory PF and CF synapses on Purkinje cells, the location of inhibitory synapses is more varied. Stellate cells form synapses over a wide area of the dendritic tree, and basket cell terminals form specialized 
As
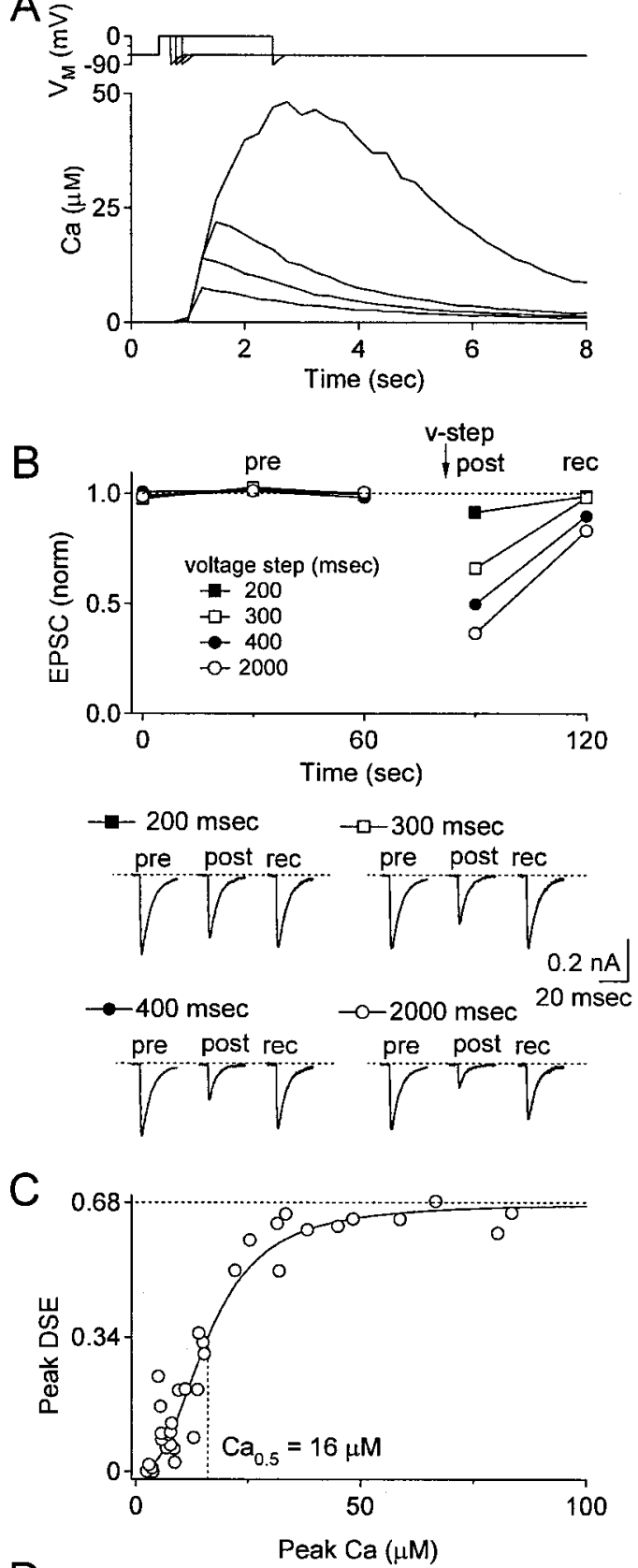

$\mathrm{D}$

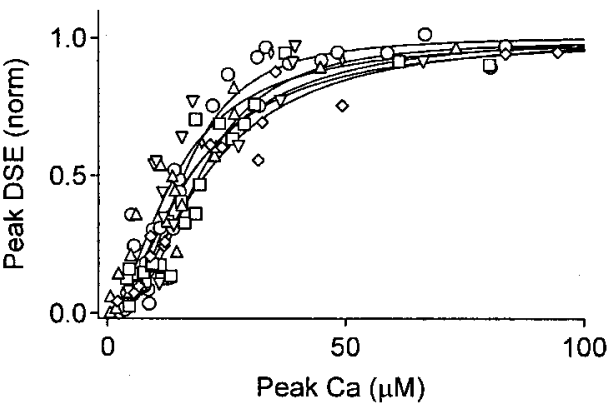

Figure 6. Calcium dependence of DSE at the climbing fiber to Purkinje cell synapse. A, DSE was evoked with Purkinje cell depolarizations of $200-2000$ msec (top), which evoked calcium transients measured in proximal dendrites (bottom). B, EPSCS were evoked at 30 sec intervals. EPSCs marked post and rec were evoked at 5 and $35 \mathrm{sec}$ after the termination of the voltage step. C, Peak DSE was calculated for each trial as $1-$ (EPSC $_{\text {post }} /$ EPSC $_{\text {pre }}$ ) and plotted against peak $\mathrm{Ca}_{\text {post }}$. DSE $\mathrm{max}_{\text {max }}$ and $\mathrm{Ca}_{0.5}$ are indicated by horizontal and vertical dashed lines, respectively. Data from $A$ and $B$ were obtained from four consecutive trials. Data from $A-C$ were obtained from one arbors in axosomatic regions. In our experiments, IPSCs were evoked at $0.5 \mathrm{~Hz}$ with a stimulus electrode placed in the molecular layer. DSI was quantified by measuring inhibition of evoked IPSCs (eIPSCs) evoked 3-7 sec after the depolarization in the same manner as measurements of PF DSE. We measured calcium transients (Fig. 7A) and inhibition of eIPSCs (Fig. 7B) in Purkinje cells after depolarizations of different durations. Dendritic calcium transients were measured near the location of the stimulus electrode, but the location of the activated synapses was not certain. Data from one cell are shown in Figure $7 A-C$. Depolarizations that ranged from 150 to 1500 msec produced increasing DSI (Fig. $7 B$ ). As in previous experiments, voltage step protocols were repeated to determine the relationship between $\mathrm{Ca}_{\text {post }}$ and DSI. Results from a single neuron are shown in Figure $7 \mathrm{C}$. Halfmaximal DSI in this cell occurred at $\mathrm{Ca}_{\text {post }}=14.5 \mu \mathrm{M}$, and the Hill coefficient was 1.0. Maximal DSI was 0.80 . This experiment was repeated on four neurons (Fig. 7D). For these cells, DSI was half-maximal at $\mathrm{Ca}_{\text {post }}=16.0 \pm 0.7 \mu \mathrm{M}$ and had a Hill coefficient of $1.3 \pm 0.1$. The maximal extent of DSI was $0.82 \pm 0.01$. We conclude that the calcium sensitivity of DSI is very similar to that of both PF and CF DSE.

\section{Discussion}

Our primary finding is that half-maximal retrograde inhibition by endocannabinoids occurs with postsynaptic calcium levels of $\sim 15 \mu \mathrm{M}$ at excitatory and inhibitory synapses onto Purkinje cells. In addition, DSE at PF and CF synapses had Hill coefficients of $2-2.3$, indicating a moderate degree of cooperativity between $\mathrm{Ca}_{\text {post }}$ and retrograde endocannabinoid inhibition. The high requirement for calcium shown in this study suggests that release of endocannabinoids by Purkinje cells may occur only in localized regions of dendrites that experience large elevations of calcium.

\section{Quantifying calcium levels within Purkinje cells}

The approach that we took to quantify dendritic calcium transients in Purkinje cells has general implications for the fluorometric measurements of calcium levels for cells in brain slices. The key steps were to perform both cuvette and in situ calibrations and to assess the responses of ratiometric indicators by simultaneously monitoring responses of the single-wavelength indicator fluo-5N. First, we selected the indicators with the appropriate sensitivities and found that fura- $2 \mathrm{FF}$ and mag-fura- 5 were both appropriate for measuring calcium transients evoked by depolarizations of sufficient duration to produce retrograde synaptic inhibition. In contrast, fura- 2 was not appropriate because it readily saturated during brief voltage steps as a consequence of its high affinity. The dissociation constant of fura-2FF $(7.7 \mu \mathrm{M})$ makes it well suited to measuring calcium transients $<5$ $\mu \mathrm{M}$ that enabled us to resolve the steep cooperativity of the relationship between $\mathrm{Ca}_{\text {post }}$ and DSE. Second, we determined $R_{\max }$ in situ for fura-2, fura2-FF, and mag-fura- 5 by using a calcium ionophore to increase $\mathrm{Ca}_{\text {post }}$ and used fluo- $5 \mathrm{~N}$ to ensure that $\mathrm{Ca}_{\text {post }}$ had been elevated sufficiently. Finally, we assessed whether binding to protein might affect the sensitivity of indicators within Purkinje cells. Although in cuvette measurements the addition of protein increased the $K_{\mathrm{D}}$ of fura- 2 , fura- $2 \mathrm{FF}$, and mag-fura- 5 , the

$\leftarrow$

cell. In this cell, half-maximal DSE occurred at Ca $a_{\text {post }}=16 \mu \mathrm{m}$, cooperativity was 2.6, and DSE $_{\max }$ was 0.68. D, Data from six cells, as obtained in C. Each cell is indicated by a different plot symbol, and fits of the Hill equation for each cell are superimposed. For six cells, half-maximal DSE occurred at peak $C_{\text {post }}=18.5 \pm 0.7 \mu \mathrm{m}$, cooperativity was $2.0 \pm 0.2$, and DSE max $_{\text {mas }}$ $0.47 \pm 0.08$ 
A
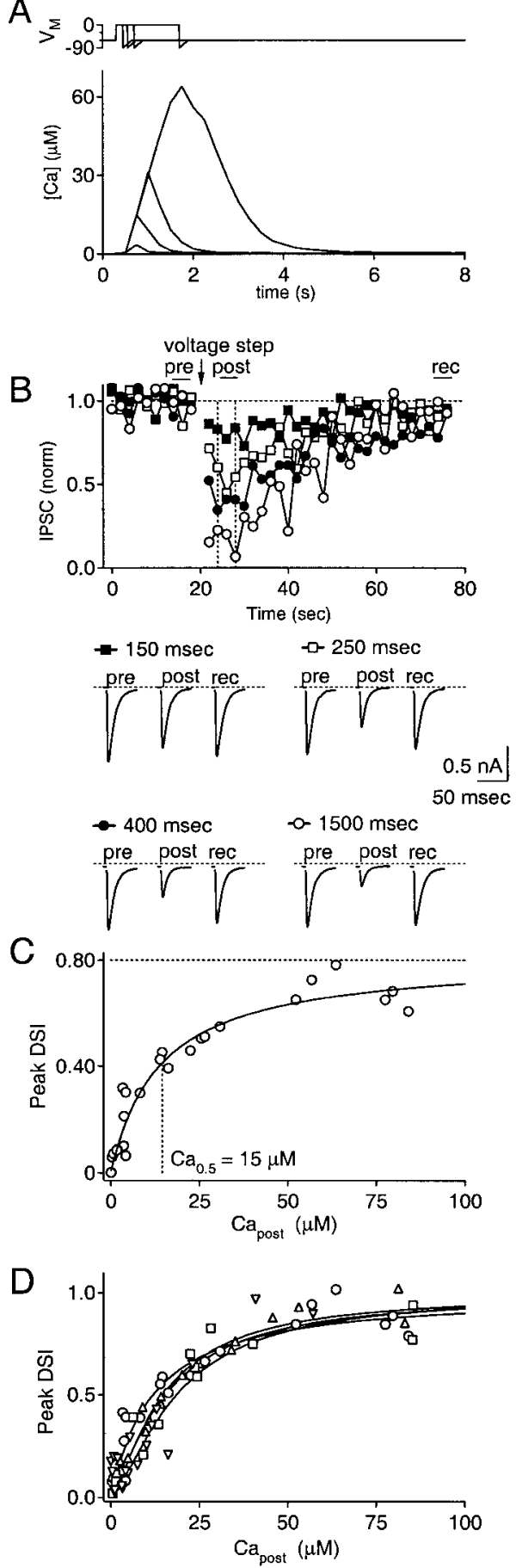

Figure 7. Calcium dependence of DSI atinhibitory synapses on Purkinjecells. $A, D S I$ was evoked by voltage steps of $150-1500 \mathrm{msec}$ (top), and resulting calcium transients are shown below (bottom). $B$, (top) IPSCs were evoked at $0.5 \mathrm{~Hz}$. DSI was evoked by voltage steps delivered after the 10th stimulus. C, PeakDSl is plotted against peak $\mathrm{Ca}_{\text {post }}$ for each trial.DSE $\mathrm{max}_{\text {max }}$ and $\mathrm{Ca}_{0.5}$ are indicated by horizontal and vertical dashed lines, respectively. Data in $A-C$ are from one cell. Half-maximal DSI occurred at Capost $=14.5 \mu \mathrm{m}$, the hill coefficient was 1.0 , and DSI ${ }_{\max }$ was 0.80 . D, The relationship between DSI and peak $\mathrm{Ca}_{\text {post }}$ for four cells. Each cell is represented by a different plot symbol, and fits of data from each cell to the Hill equation are shown. For four cells, half-maximal DSI occurred at peak $\mathrm{Ca}_{\text {post }}=16.0 \pm$ $0.7 \mu \mathrm{M}$, cooperativity was $1.3 \pm 0.1$, and DSI $I_{\max }$ was $0.82 \pm 0.01$.

$K_{\mathrm{D}}$ of fluo- $5 \mathrm{~N}$ was unaffected. We took advantage of this insensitivity of fluo- $5 \mathrm{~N}$ to determine the appropriate dissociation constants for fura- 2 FF and mag-fura-5 in Purkinje cells. Our results suggest that neither of these indicators undergoes a shift in affin- ity within Purkinje cells. By eliminating a three- to fourfold uncertainty in the $K_{\mathrm{D}}$, we were better able to determine $\mathrm{Ca}_{\text {post }}$.

\section{Calcium dependence of retrograde inhibition}

We found similarities and differences in the $\mathrm{Ca}_{\text {post }}$ dependence of retrograde inhibition at the three synapses that we studied. Although $\mathrm{Ca}_{0.5}$ was similar at all of the synapses $(\sim 15 \mu \mathrm{M})$, the Hill coefficients and extent of retrograde inhibition differed. For CF and PF synapses the Hill coefficient was $2-2.3$, whereas it was only 1.3 for inhibitory synapses. The maximal extent of inhibition ranged from a reduction of $89 \%$ for PF synapses to $82 \%$ for inhibitory synapses and $47 \%$ for CF synapses.

In considering the factors underlying such differences in the extent and $\mathrm{Ca}_{\text {post }}$ dependence of retrograde inhibition, it is necessary to consider the many steps between the initial elevation in $\mathrm{Ca}_{\text {post }}$ and the reduction in synaptic strength. (1) Endocannabinoids are synthesized and released in a calcium-dependent manner (Devane et al., 1992; Di Marzo et al., 1994; Stella et al., 1997). (2) After their liberation, endocannabinoids must diffuse to the presynaptic terminal. Factors determining the amplitude and duration of endocannabinoid signal available to activate presynaptic receptors include diffusion, uptake, and degradation (Cravatt et al., 1996; Beltramo et al., 1997; Di Marzo et al., 1998). (3) Endocannabinoids then bind to presynaptic CB1 receptors, which leads to (4) the inhibition of presynaptic calcium channels (Kreitzer and Regehr, 2001b; Diana et al., 2002; Howlett et al., 2002), which in turn (5) reduces the release of neurotransmitter (Levenes et al., 1998; Takahashi and Linden, 2000; Kreitzer and Regehr, 2001a,b), ultimately leading to a reduction in the postsynaptic response. Although little is known about steps 1-3, much is known about the relationship between presynaptic calcium influx $\left(\mathrm{Ca}_{\text {pre }}\right)$ and EPSC amplitude at PF and CF synapses. The relationship between $\mathrm{Ca}_{\text {pre }}$ and EPSC amplitude at PF and CF synapses is different. Notably, at the PF synapse there is a power-law dependence of the EPSC on $\mathrm{Ca}_{\text {pre }}$ (Mintz et al., 1995; Sabatini and Regehr, 1997), whereas at the CF synapse this relationship exhibits saturation (Fig. 8Aa,Ba) (Foster et al., 2002). These differences in the dependence of EPSCs on $\mathrm{Ca}_{\text {pre }}$ will differentially influence the manner in which modulation of $\mathrm{Ca}_{\text {pre }}$ by endocannabinoids ultimately affects the EPSC at PF and CF synapses.

We therefore assessed how the relationship between $\mathrm{Ca}_{\text {pre }}$ and EPSCs influences the Hill coefficient, the $\mathrm{Ca}_{\text {post }}$ sensitivity, and the extent of retrograde inhibition at PF and CF synapses. For PF and CF synapses, we used the known relationship between $\mathrm{Ca}_{\text {pre }}$ and EPSC amplitude (Fig. 8Aa,Ba) and our experimentally determined measurement of the dependence of DSE on $\mathrm{Ca}_{\text {post }}$ (Fig. $8 A b, B b)$ to express modulation of $\mathrm{Ca}_{\text {pre }}$ as a function of $\mathrm{Ca}_{\text {post }}$ during retrograde inhibition (Fig. $8 A c, B c$ ). Although multiple mechanisms may contribute to endocannabinoid modulation, at the PF and CF synapses the effects of endocannabinoids reflect a reduction of presynaptic calcium influx (Kreitzer and Regehr, 2001b; S. Brown and W. Regehr, unpublished observations), and there is no evidence for cannabinoid-mediated effects downstream of calcium influx (Takahashi and Linden, 2000). Therefore, this analysis allows us to examine the ability of endocannabinoids to directly modulate presynaptic calcium influx. Although DSE max $_{\text {was }} 89$ and $47 \%$ for PF and CF synapses, respectively, the underlying retrograde inhibition of $\mathrm{Ca}_{\text {pre }}$ was 52 and $42 \%$ for PF and CF synapses. This indicates that although inhibition of presynaptic calcium is similar at PF and CF synapses, the difference in the relationship between $\mathrm{Ca}_{\text {pre }}$ and EPSC 
Aa
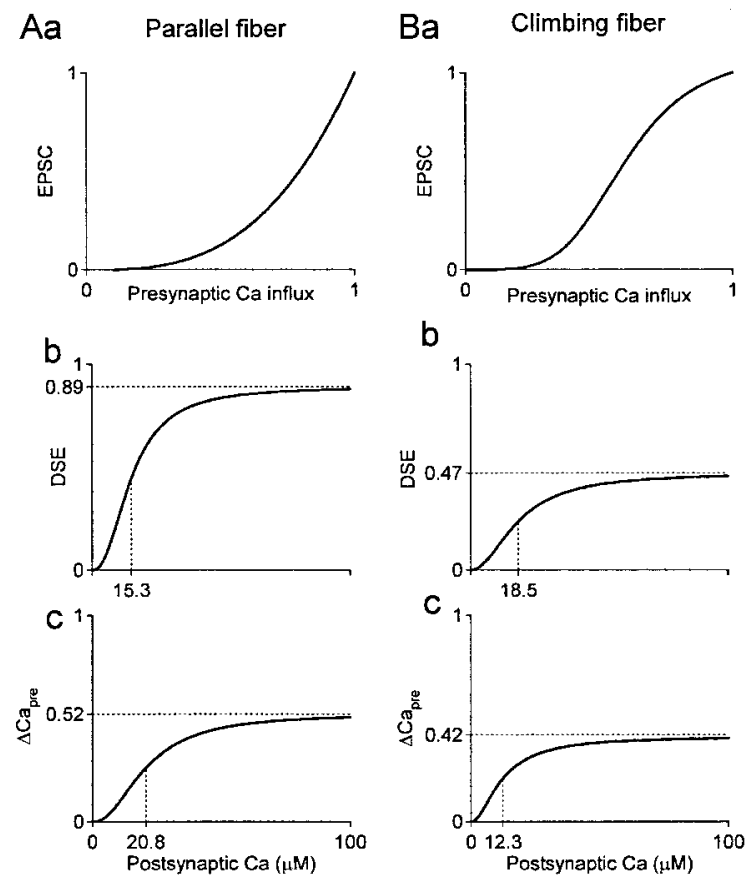

Figure 8. Contributions of the relationship between $\mathrm{Ca}_{\text {pre }}$ and EPSC to the $\mathrm{Ca}_{\text {post }}$ dependence of retrograde inhibition. $A a$, Dependence of the EPSC on Ca $a_{\text {pre }}$ at parallel fiber synapses, which is described by an equation of the form EPSC $=k\left(\mathrm{Ca}_{\text {pre }}\right)^{3}$. Ab, Relationship between PF-DSE and $C a_{\text {post }}$, which is described by DSE $=D S E_{\max } /\left(1+\left(\left(a_{0.5} /\left(a_{\text {post }}\right)^{n}\right)\right.\right.$. Parameters of this plot are from Figure $5 A$, with DSE $E_{\max }=0.89, \mathrm{Ca}_{0.5}=15.3$, and $n=2.3$. Ac, We next used the power law, above, to calculate the relationship between endocannabinoid-mediated inhibition of $\mathrm{Ca}_{\text {pre }}$ and $\mathrm{Ca}_{\text {post }}$. $\mathrm{Ca}_{\text {pre }}$ was calculated using $\mathrm{Aa}$ and $A b$. Maximum inhibition of $\mathrm{Ca}_{\text {pre }}$ is $52 \%$, inhibition of $\mathrm{Ca}_{\text {pre }}$ is half-maximal with $\mathrm{Ca}_{\text {post }}=20.8 \mu \mathrm{m}$, and the Hill coefficient of 2.0. $\mathrm{Ba}$, Dependence of the CFEPSC on $C_{\text {pre }}$, which is described by EPSC $=1.1\left(\left(C_{\text {pre }}{ }^{n} /\left(C_{\text {pre }}{ }^{n}+K_{D}{ }^{n}\right)\right.\right.$, where $n=4.5$ and $K_{\mathrm{D}}=0.6 \mathrm{~mm}$ (Foster et al., 2002). Bb, The relationship between climbing fiber DSE and $C_{\text {post }}$ from Figure $6 D$. The relation has the same form as in $A b$, and the parameters are $D S E_{\max }=0.47, \mathrm{Ca}_{0.5}=18.5$, and $n=2.0 . B c$, As in $A$ of this figure, we determined the relationship between endocannabinoid-mediated inhibition of $\mathrm{Ca}_{\text {pre }}$ versus elevation of $\mathrm{Ca}_{\text {post }}$ at climbing fiber synapses. Maximum inhibition of $\mathrm{Ca}_{\text {pre }}$ is $42 \%$, inhibition of $\mathrm{Ca}_{\text {pre }}$ is halfmaximal with $\mathrm{Ca}_{\text {post }}=12.3 \mu \mathrm{m}$, and the Hill coefficient is 1.8 .

amplitudes produces large differences between $\mathrm{DSE}_{\max }$ at $\mathrm{PF}$ and CF synapses.

We also found that the relationship between $\mathrm{Ca}_{\text {pre }}$ and EPSC amplitude at $\mathrm{PF}$ versus $\mathrm{CF}$ synapses altered the apparent $\mathrm{Ca}_{\text {post }}$ sensitivity of retrograde inhibition. At PF synapses, $\mathrm{Ca}_{0.5}$ for inhibition of EPSCs and for inhibition of $\mathrm{Ca}_{\text {pre }}$ was 15.3 and 20.9 $\mu \mathrm{M}$, respectively. At CF synapses, $\mathrm{Ca}_{0.5}$ for inhibition of EPSCs and $\mathrm{Ca}_{\text {pre }}$ was 18.5 and $12.3 \mu \mathrm{M}$, respectively. This comparison of postsynaptic calcium required for half-maximal inhibition of EPSCs versus $\mathrm{Ca}_{\text {pre }}$ revealed that at a saturating synapse such as $\mathrm{CF}$ synapses, the $\mathrm{Ca}_{\text {post }}$ required for half-maximal inhibition of $\mathrm{Ca}_{\text {pre }}$ compared with inhibition of EPSCs shifts to lower values and at a nonsaturating synapse such as PF synapses the shift is to higher values. Thus, the relationship between $\mathrm{Ca}_{\text {pre }}$ and EPSC amplitude alters the $\mathrm{Ca}_{\text {post }}$ dependence of retrograde inhibition, but the effects are small.

The final issue that we addressed was the source of cooperativity in endocannabinoid-mediated retrograde inhibition. We considered the possibility that the steep relationship between $\mathrm{Ca}_{\text {pre }}$ and the EPSC might account for steep Hill coefficients of $2-2.3$ for the relationship between $\mathrm{Ca}_{\text {post }}$ and DSE. On the basis of the analysis in Figure 8, however, we found that the cooperativity changes only slightly when we consider the effects of $\mathrm{Ca}_{\text {post }}$ on
$\mathrm{Ca}_{\text {pre }}$, shifting the Hill coefficients to $1.8-2.0$, thus indicating that the cooperativity of DSE occurs at a stage before presynaptic calcium influx. This is consistent with previous studies that found varying degrees of cooperativity (Hill coefficients of 1.2-3) in channel modulation by neurotransmitters (Ito et al., 1992; Krapivinsky et al., 1995; Sodickson and Bean, 1996, 1998). The calcium dependence of endocannabinoid synthesis and release may also be cooperative, contributing to the steep dependence of retrograde inhibition on postsynaptic calcium.

The Hill coefficient that we measured for the relationship between $\mathrm{Ca}_{\text {post }}$ and DSI was 1.3, consistent with values of 1.3 and 1 reported previously for DSI in hippocampus and cerebellum, respectively (Glitsch et al., 2000; Wang and Zucker, 2001). This suggests the intriguing possibility that there may be less cooperativity at inhibitory relative to excitatory synapses. However, because the locations of interneuron synapses are difficult to determine, there is ambiguity regarding the precise region of dendrites in which to measure calcium. This may introduce uncertainty to the measurements of calcium dependence of DSI.

\section{Functional implications}

The high $\mathrm{Ca}_{\text {post }}$ levels required for retrograde inhibition and the Hill coefficients of $\sim 2$ for DSE at PF and CF synapses indicate that calcium-dependent retrograde inhibition at excitatory synapses has a high activation threshold. For example, an elevation of $\mathrm{Ca}_{\text {post }}$ to $5 \mu \mathrm{M}$ results in only $6 \%$ inhibition of PF EPSCs, whereas an elevation of $\mathrm{Ca}_{\text {post }}$ to $25 \mu \mathrm{m}$ inhibits PF EPSCs by $67 \%$.

Additional factors may also be important under physiological conditions. To accurately determine the $\mathrm{Ca}_{\text {post }}$ dependence of retrograde inhibition, we performed experiments at room temperature in young animals in the absence of metabotropic receptor activation. Considering the many steps between elevation of $\mathrm{Ca}_{\text {post }}$ and retrograde inhibition, it is likely that the $\mathrm{Ca}_{\text {post }}$ dependence of retrograde inhibition differs somewhat at physiological temperatures. The $\mathrm{Ca}_{\text {post }}$ dependence may also be developmentally regulated. Last, recent studies point to a role for metabotropic glutamate and acetylcholine receptors in potentiating $\mathrm{Ca}_{\text {post }}$-dependent release in evoking release through calciumindependent mechanisms (Varma et al., 2001; Kim et al., 2002; Ohno-Shosaku et al., 2002; Yoshida et al., 2002).

To more fully appreciate the functional implications of the $\mathrm{Ca}_{\text {post }}$ dependence of endocannabinoid release, it is necessary to know the magnitude and spatial location of dendritic calcium signals under different physiological conditions. Numerous studies have shown that calcium signals in Purkinje cells arise from spontaneous activity and synaptic activation, both of which can open voltage-gated calcium channels and release calcium from internal stores (Tank et al., 1988; Mikawa et al., 1997; Finch and Augustine, 1998; Takechi et al., 1998). These studies indicate that calcium signals in Purkinje cell dendrites can be widespread and that there are also mechanisms that provide spatially localized signaling. Many of these studies, however, focused on spatial and temporal aspects of calcium signaling, and it remains an open question just how high $\mathrm{Ca}_{\text {post }}$ gets under physiological conditions and what means of Purkinje cell activation can elevate calcium levels sufficiently to reach the tens of micromolar levels sufficient to evoke endocannabinoid release.

\section{References}

Atluri PP, Regehr WG (1996) Determinants of the time course of facilitation at the granule cell to Purkinje cell synapse. J Neurosci 16:5661-5671.

Baylor SM, Hollingworth S (1988) Fura-2 calcium transients in frog skeletal muscle fibres. J Physiol (Lond) 403:151-192. 
Beltramo M, Stella N, Calignano A, Lin SY, Makriyannis A, Piomelli D (1997) Functional role of high-affinity anandamide transport, as revealed by selective inhibition. Science 277:1094-1097.

Cravatt BF, Giang DK, Mayfield SP, Boger DL, Lerner RA, Gilula NB (1996) Molecular characterization of an enzyme that degrades neuromodulatory fatty-acid amides. Nature 384:83-87.

Devane WA, Hanus L, Breuer A, Pertwee RG, Stevenson LA, Griffin G, Gibson D, Mandelbaum A, Etinger A, Mechoulam R (1992) Isolation and structure of a brain constituent that binds to the cannabinoid receptor. Science 258:1946-1949.

Diana MA, Levenes C, Mackie K, Marty A (2002) Short-term retrograde inhibition of GABAergic synaptic currents in rat Purkinje cells is mediated by endogenous cannabinoids. J Neurosci 22:200-208.

Di Marzo V, Fontana A, Cadas H, Schinelli S, Cimino G, Schwartz JC, Piomelli D (1994) Formation and inactivation of endogenous cannabinoid anandamide in central neurons. Nature 372:686-691.

Di Marzo V, Bisogno T, Sugiura T, Melck D, De Petrocellis L (1998) The novel endogenous cannabinoid 2-arachidonoylglycerol is inactivated by neuronal- and basophil-like cells: connections with anandamide. Biochem J 331:15-19.

Doherty J, Dingledine R (2003) Functional interactions between cannabinoid and metabotropic glutamate receptors in the central nervous system. Curr Opin Pharmacol 3:46-53.

Eccles JC, Llinas R, Sasaki K, Voorhoeve PE (1966) Interaction experiments on the responses evoked in Purkinje cells by climbing fibres. J Physiol (Lond) 182:297-315.

Erdahl WL, Chapman CJ, Taylor RW, Pfeiffer DR (1995) Effects of pH conditions on $\mathrm{Ca}^{2+}$ transport catalyzed by ionophores A23187, 4-BrA23187, and ionomycin suggest problems with common applications of these compounds in biological systems. Biophys J 69:2350-2363.

Finch EA, Augustine GJ (1998) Local calcium signaling by inositol-1,4,5trisphosphate in Purkinje cell dendrites. Nature 396:753-756.

Foster KA, Kreitzer AC, Regehr WG (2002) Interaction of postsynaptic receptor saturation with presynaptic mechanisms produces a reliable synapse. Neuron 36:1115-1126.

Glitsch M, Parra P, Llano I (2000) The retrograde inhibition of IPSCs in rat cerebellar Purkinje cells is highly sensitive to intracellular $\mathrm{Ca}^{2+}$. Eur J Neurosci 12:987-993.

Grynkiewicz G, Poenie M, Tsien RY (1985) A new generation of $\mathrm{Ca}^{2+}$ indicators with greatly improved fluorescence properties. J Biol Chem 260:3440-3450.

Harkins AB, Kurebayashi N, Baylor SM (1993) Resting myoplasmic free calcium in frog skeletal muscle fibers estimated with fluo-3. Biophys J 65:865-881.

Howlett AC, Barth F, Bonner TI, Cabral G, Casellas P, Devane WA, Felder CC, Herkenham M, Mackie K, Martin BR, Mechoulam R, Pertwee RG (2002) International Union of Pharmacology. XXVII. Classification of cannabinoid receptors. Pharmacol Rev 54:161-202.

Ito H, Tung RT, Sugimoto T, Kobayashi I, Takahashi K, Katada T, Ui M, Kurachi Y (1992) On the mechanism of G protein beta gamma subunit activation of the muscarinic $\mathrm{K}+$ channel in guinea pig atrial cell membrane. Comparison with the ATP-sensitive K+ channel. J Gen Physiol 99:961-983.

Khodakhah K, Armstrong CM (1997) Inositol trisphosphate and ryanodine receptors share a common functional $\mathrm{Ca}^{2+}$ pool in cerebellar Purkinje neurons. Biophys J 73:3349-3357.

Kim J, Isokawa M, Ledent C, Alger BE (2002) Activation of muscarinic acetylcholine receptors enhances the release of endogenous cannabinoids in the hippocampus. J Neurosci 22:10182-10191.

Konishi M, Olson A, Hollingworth S, Baylor SM (1988) Myoplasmic binding of fura-2 investigated by steady-state fluorescence and absorbance measurements. Biophys J 54:1089-1104.

Krapivinsky G, Krapivinsky L, Wickman K, Clapham DE (1995) G beta gamma binds directly to the $\mathrm{G}$ protein-gated $\mathrm{K}+$ channel, IKACh. J Biol Chem 270:29059-29062.

Kreitzer AC, Regehr WG (2001a) Cerebellar depolarization-induced suppression of inhibition is mediated by endogenous cannabinoids. J Neurosci 21:RC174(1-5).

Kreitzer AC, Regehr WG (2001b) Retrograde inhibition of presynaptic calcium influx by endogenous cannabinoids at excitatory synapses onto Purkinje cells. Neuron 29:717-727.
Kreitzer AC, Regehr WG (2002) Retrograde signaling by endocannabinoids. Curr Opin Neurobiol 12:324-330.

Kreitzer AC, Carter AG, Regehr WG (2002) Inhibition of interneuron firing extends the spread of endocannabinoid signaling in the cerebellum. Neuron 34:787-796.

Kurebayashi N, Harkins AB, Baylor SM (1993) Use of fura red as an intracellular calcium indicator in frog skeletal muscle fibers. Biophys J 64:1934-1960.

Lenz RA, Alger BE (1999) Calcium dependence of depolarization-induced suppression of inhibition in rat hippocampal CA1 pyramidal neurons. J Physiol (Lond) 521:147-157.

Lenz RA, Wagner JJ, Alger BE (1998) N- and L-type calcium channel involvement in depolarization-induced suppression of inhibition in rat hippocampal CA1 cells. J Physiol (Lond) 512:61-73.

Levenes C, Daniel H, Soubrie P, Crepel F (1998) Cannabinoids decrease excitatory synaptic transmission and impair long-term depression in rat cerebellar Purkinje cells. J Physiol (Lond) 510:867-879.

Mackie K, Hille B (1992) Cannabinoids inhibit N-type calcium channels in neuroblastoma-glioma cells. Proc Natl Acad Sci USA 89:3825-3829.

Mackie K, Devane WA, Hille B (1993) Anandamide, an endogenous cannabinoid, inhibits calcium currents as a partial agonist in N18 neuroblastoma cells. Mol Pharmacol 44:498-503.

Maejima T, Hashimoto K, Yoshida T, Aiba A, Kano M (2001) Presynaptic inhibition caused by retrograde signal from metabotropic glutamate to cannabinoid receptors. Neuron 31:463-475.

Matsuda LA, Lolait SJ, Brownstein MJ, Young AC, Bonner TI (1990) Structure of a cannabinoid receptor and functional expression of the cloned cDNA. Nature 346:561-564.

Mikawa Y, Matsuda S, Kanagawa T, Tajika T, Ueda N, Mimura Y (1997) Ocular activity of topically administered anandamide in the rabbit. Jpn J Ophthalmol 41:217-220.

Mintz IM, Sabatini BL, Regehr WG (1995) Calcium control of transmitter release at a cerebellar synapse. Neuron 15:675-688.

Ohno-Shosaku T, Sawada S, Yamamoto C (1998) Properties of depolarization-induced suppression of inhibitory transmission in cultured rat hippocampal neurons. Pflügers Arch 435:273-279.

Ohno-Shosaku T, Maejima T, Kano M (2001) Endogenous cannabinoids mediate retrograde signals from depolarized postsynaptic neurons to presynaptic terminals. Neuron 29:729-738.

Ohno-Shosaku T, Shosaku J, Tsubokawa H, Kano M (2002) Cooperative endocannabinoid production by neuronal depolarization and group I metabotropic glutamate receptor activation. Eur J Neurosci 15:953-961.

Palay SL, Chan-Palay V (1974) Cerebellar cortex: cytology and organization. New York: Springer.

Pitler TA, Alger BE (1992) Postsynaptic spike firing reduces synaptic GABAA responses in hippocampal pyramidal cells. J Neurosci 12:4122-4132.

Ross WN, Werman R (1987) Mapping calcium transients in the dendrites of Purkinje cells from the guinea-pig cerebellum in vitro. J Physiol (Lond) 389:319-336.

Sabatini BL, Regehr WG (1997) Control of neurotransmitter release by presynaptic waveform at the granule cell to Purkinje cell synapse. J Neurosci 17:3425-3435.

Sodickson DL, Bean BP (1996) GABAB receptor-activated inwardly rectifying potassium current in dissociated hippocampal CA3 neurons. J Neurosci 16:6374-6385.

Sodickson DL, Bean BP (1998) Neurotransmitter activation of inwardly rectifying potassium current in dissociated hippocampal CA3 neurons: interactions among multiple receptors. J Neurosci 18:8153-8162.

Stella N, Schweitzer P, Piomelli D (1997) A second endogenous cannabinoid that modulates long-term potentiation. Nature 388:773-778.

Takahashi KA, Linden DJ (2000) Cannabinoid receptor modulation of synapses received by cerebellar Purkinje cells. J Neurophysiol 83:1167-1180.

Takechi H, Eilers J, Konnerth A (1998) A new class of synaptic response involving calcium release in dendritic spines. Nature 396:757-760.

Tank DW, Sugimori M, Connor JA, Llinas RR (1988) Spatially resolved calcium dynamics of mammalian Purkinje cells in cerebellar slice. Science 242:773-777.

Tsien R, Pozzan T (1989) Measurement of cytosolic free calcium with quin 2. Methods Enzymol 172:230-262. 
Twitchell W, Brown S, Mackie K (1997) Cannabinoids inhibit N- and P/Qtype calcium channels in cultured rat hippocampal neurons. J Neurophysiol 78:43-50.

Varma N, Carlson GC, Ledent C, Alger BE (2001) Metabotropic glutamate receptors drive the endocannabinoid system in hippocampus. J Neurosci 21:RC188(1-4).

Wang E, Taylor RW, Pfeiffer DR (1998) Mechanism and specificity of lanthanide series cation transport by ionophores A23187, 4-BrA23187, and ionomycin. Biophys J 75:1244-1254.

Wang J, Zucker RS (2001) Photolysis-induced suppression of inhibition in rat hippocampal CA1 pyramidal neurons. J Physiol (Lond) 533:757-763.

Wang SS, Denk W, Hausser M (2000) Coincidence detection in single dendritic spines mediated by calcium release. Nat Neurosci 3:1266-1273.
Wilson RI, Nicoll RA (2001) Endogenous cannabinoids mediate retrograde signaling at hippocampal synapses. Nature 410:588-592.

Wilson RI, Nicoll RA (2002) Endocannabinoid signaling in the brain. Science 296:678-682.

Xu-Friedman MA, Regehr WG (1999) Presynaptic strontium dynamics and synaptic transmission. Biophys J 76:2029-2042.

Xu-Friedman MA, Harris KM, Regehr WG (2001) Three-dimensional comparison of ultrastructural characteristics at depressing and facilitating synapses onto cerebellar Purkinje cells. J Neurosci 21:6666-6672.

Yoshida T, Hashimoto K, Zimmer A, Maejima T, Araishi K, Kano M (2002) The cannabinoid CB1 receptor mediates retrograde signals for depolarization-induced suppression of inhibition in cerebellar Purkinje cells. J Neurosci 22:1690-1697. 